\title{
Modelling the bond in GFRP bar reinforced concrete thin structural members
}

\author{
Ana Veljkovic $^{\mathrm{a}}$, Valter Carvelli ${ }^{\mathrm{a}, *}$, Mohammadali Rezazadeh $^{\mathrm{b}}$ \\ a Department of Architecture, Built Environment and Construction Engineering, Politecnico di Milano, Piazza Leonardo da Vinci 32, 20133 Milan, Italy \\ ${ }^{\mathrm{b}}$ ISISE, Structural Division of the Department of Civil Engineering, University of Minho, 4800-058 Guimaraes, Portugal
}

\section{A R T I C L E I N F O}

Keywords

GFRP bar

RC slab

FEM modelling

Bond

Concrete mechanical models

Debonding

\begin{abstract}
A B S T R A C T
This paper analyses the accuracy of FE (Finite Element) modelling of concrete thin slabs, reinforced with GFRP (Glass Fiber Reinforced Polymer) bars, under bending loading conditions. It considers two strategies of concrete/ bar interaction approach - direct and indirect. Indirect bond approach was combined with concrete tension stiffening model, whereas the direct bond one employed plain concrete constitutive model. Apart from selection of material and bond models, FE mesh sensitivity was examined. The efficiency of both bond modelling strategies was proven for the slab of standard thickness $(100 \mathrm{~mm})$ failed due to concrete crushing, whereas direct bond method was shown indispensable when simulating very thin slabs $(40 \mathrm{~mm})$ failed due to bar debonding.
\end{abstract}

\section{Introduction}

The intrinsic nature of RC (Reinforced Concrete) is primarily based on the bond between concrete and reinforcing bars. The bond provides transfer of forces from reinforcement to surrounding concrete. In addition, bond properties influence strength of laps and anchorages at ultimate limit states, and crack widths and deflections at serviceability limit states [1]. Therefore, it is considered as one of the most important issues in RC design [2].

The effect of bond-slip on RC structural performance is usually accounted for in two ways: direct and indirect. Former incorporates directly the bond-slip law into calculation, while later assumes perfect bond hypothesis, which means no slipping occurrence between the bar and the concrete. The simplification made by using a perfect bond is usually overcome by implementing tension stiffening effect [3]. Tension stiffening considers the capacity of concrete to carry tensile stresses between the cracks, which contributes to the global stiffness of RC structure and it is important especially for the behavior under service loadings [4].

Tension stiffening can be incorporated in design by modifying concrete post-cracking stress-strain response [5,6]. This so-called 'load sharing' approach is very widely used, and different shapes of such tension-stiffening laws for concrete reinforced with steel bars are proposed by many authors [7-12]. Instead, when bond-slip law is directly incorporated in design, the corresponding concrete post-cracking response accounts only for the behavior of concrete material itself [13]. This model describes the crack growth in concrete and it is characterized by the tension softening behavior. Such models were proposed first by Hillerborg et al. [14], based on the fictitious crack model, and by Bazant and Oh [15], based on the crack band theory. Nowadays, frequently used is the one adopted by fib MC (Model Code) in a form of post-cracking stress-crack opening law $[1,3]$.

Both approaches, direct and indirect, involve advantages and drawbacks. Direct approach is by common sense preferable to be used, but it includes difficulties in calculation and related time consumption. Indirect approach is easier to be implemented, but it could result in output inaccuracies. Parametric studies performed on RC members reinforced with traditional steel bars [16] have shown the importance of direct bond-slip inclusion into prediction of the behavior under static bending loading.

The FRP (Fiber Reinforced Polymer) bars found their application as a new type of reinforcement for concrete structures instead of traditionally used steel bars. The main advantages of FRP bars, over the steel ones, are reflected in FRP's noncorrosive nature, magnetic transparency and high strength-to-weight ratio [17]. Not only for different mechanical and physical characteristics of reinforcement, but also for the different mechanisms involved in bond with concrete, FRP RC design could be considered as a distinct research field. The bond of FRP bars with concrete is still the subject of many research studies [18-20]. Although the importance of bond action is highly emphasized and the debonding is marked as one of the relevant failure modes in FRP RC structures [21], in many studies the direct implementation is neglected, and structure is modelled assuming perfect bond between concrete and FRP bar [22]. Debonding of FRP bars is marked as one of the design checks [23], because FRP bar/concrete bond might be simi-

\footnotetext{
* Corresponding author.

E-mail address: valter.carvelli@polimi.it (V. Carvelli)
} 
lar, but generally has weaker characteristics comparing to the bond of concrete with steel bars [24]. This aspect becomes more relevant considering the good durability of FRP material and, hence, the attempt to minimize the concrete cover, concerning its role as a protective layer. However, small cover could affect the proper stress transfer from FRP bar to concrete and special attention must be paid to it. Not only debonding as a failure mode, but also bond-slip mechanism affects the FRP RC structural response [24]. To account for the small concrete cover, indirect bond method could be used if it considers the influence of splitting cracks on tension stiffening law. While some studies are available for steel reinforced concrete members [5,25], up to the authors' knowledge, there is no research about concrete splitting influence on tension stiffening in FRP RC structures.

For the estimation of bond influence on FRP RC members, the direct application of models developed for steel reinforcement was not reasonable. Bischoff and Paixao modified the existing equation for tensile response of cracked steel-reinforced concrete, to be applicable in both steel and FRP RC design [26]. Using this research and the tension stiffening law proposed by [27], Nour et al. [28] validated this concrete model by the simulation of reinforced concrete members having different layout and type of failure. Zhang and Lin [29] validated the same tension stiffening model [27], by numerical simulation of steel- and FRP-reinforced concrete beams, even with very coarse meshes. Tension stiffening laws were obtained directly from GFRP and steel reinforced beams, using an inverse analysis and considering shrinkage effects in [30]. Derived concrete tensile stress-strain constitutive laws were implemented in FE model and proved their adequacy by good agreement with the experimental results [30].

Modelling strategy that implies direct inclusion of experimental bond-slip law was validated by 3D FE model [31], in terms of experimental deformation and cracking behavior. Lin and Zhang developed composite beam FE that accounts directly for the bond-slip effect [32], using the BPE (Eligehausen, Popov and Bertero) modified bond stress-slip model [33]. The results comply with the experimental ones, also at the final loading stage when bond slip occurs, which was less accurately simulated with the perfect bond model. The important advantage of direct bond method was shown through simulation of flexural tests of beams reinforced with smooth surface FRP bars. Due to the significant amount of bars' slippage, the proper modelling was possible only by directly accounting for the bond-slip effect [24]. Jakubovskis et al. [34] considered three different bond laws to simulate GFRP beam flexural behavior: MC 2010, calibrated MC 2010 (based on bending bond tests) and the one proposed by Shima et al. [35]. The authors reported satisfactory results on prediction of cracking and deformation states, but also the inability of the bond models to give accurate predictions for all types of beams in the study. 2D FE model that involves the experimental pull-out bond-slip law in predicting the flexural behavior of GFRP RC slabs was developed in [36]. The study demonstrated better agreement with the experimental load-deflection curve in the case

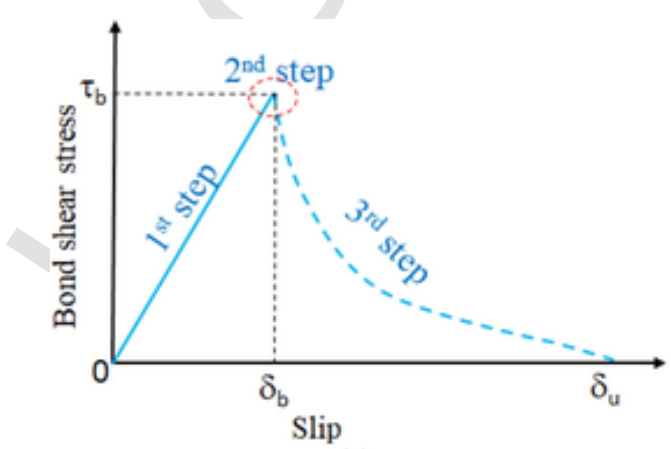

(a) of direct inclusion of bond-slip law than when perfect bond is considered, whereas the latter one is sufficiently safe for estimation of the ultimate load capacity of GFRP RC slabs.

As for the future research and tendencies of application of FRP bars as concrete reinforcement, direct bond-slip method represents an important approach to be considered for modelling and design. It is suitable to attain a ductile behavior of FRP RC structures triggering the progressive debonding between FRP bars and surrounding concrete under ultimate loading conditions [37]. Furthermore, bond-slip becomes of considerable importance when these structures are exposed to high temperatures $[38,39]$.

The main focus of this study was to contribute to the existing knowledge in the field by assessing the importance of including directly the effect of bond-slip in FRP RC structures. Since debonding is marked as one of the relevant failure modes, a bond model was implemented directly into the simulation of the structural behavior, allowing to consider this additional important failure mechanism. Particularly, some of the thin flexural members, subject of this study, failed in debonding caused by concrete cover splitting. This type of failure was a consequence of adopted small concrete cover.

This study presents a strategy for the numerical simulation of FRP RC structural components, including debonding failure. The bond behavior was implemented in a 3D FE code [40] using cohesive finite elements. The damage initiation and development at the interface was simulated considering a damage model based on the secant modulus bond degradation [41], assuming experimental data from eccentric pull-out tests [42] (Section 2). The experimental test results of thin GFRP RC members, quasi-statically loaded in flexure [43] (Section 3), were considered to assess the accuracy of the numerical modelling (Section 5). Those were selected having a complete dataset as input of the numerical analyses, which is not available in several other works in the literature. The comparison of the experimental, design guidelines (Section 4) and numerical outcomes was based on load-deflection curves, failure modes and damage patterns (Section 6). Proposed strategy was shown valid for predicting the FRP RC member flexural response, including debonding failure mode.

\section{Overview of the interface damage model}

This study considers the relation between bond shear stress, raising due to the axial force in the bar, and the corresponding slip between bar and concrete. The bond shear stress-slip law was obtained from pull-out tests and adopted to simulate the interaction between bar and concrete in GFRP RC slabs. The bond deterioration effect was modelled using a damage evolution approach as described in [41]. The shear stress-slip curve of the interface was modelled assuming: 1) an initial linear response up to the maximum bond shear stress $\left(\tau_{b}\right)-$ ascending part of the bond curve, 2) maximum of the bond curve as the damage initiation criterion, and 3) damage evolution law based on the post-peak branch of the bond curve (Fig. 1a). Bond curves with loaded-

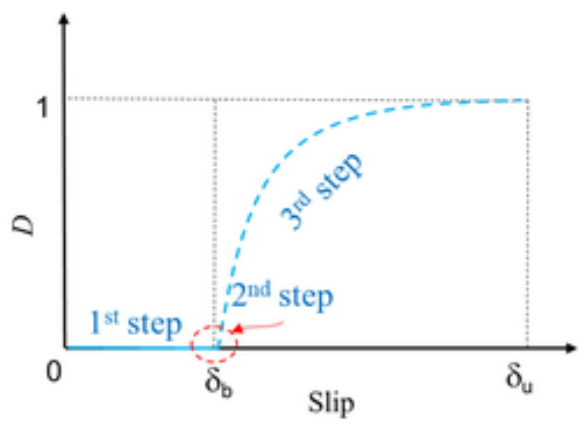

(b)

Fig. 1. (a) Typical bond curve and (b) typical damage-slip curve, and the three steps of bond damage evolution approach. 
end slip of the pull-out tests were used. First step is considered as undamaged state of bond and it lasts until bond shear stress reaches its maximum value, which is defined as a damage initiation criterion. Once the damage initiation criterion occurs, third step begins and damage propagation follows the adopted damage evolution law.

The damage evolution law was calibrated using the secant modulus damage evolution model for setting the values of a scalar damage variable $(D)$. The variable $D$ is estimated by the degradation of secant bond stiffness according to Lemaitre-based damage model [44]. The values of $D$ range between 0 (denoting no damage) and 1 (denoting complete damage) (Fig. 1b). In Fig. $1, \delta_{b}$ and $\delta_{u}$ stand for slip at damage initiation and slip at failure (complete damage), respectively. The degradation of bond stiffness is quantified measuring the ratio of the secant bond stiffness in the post-peak branch of bond curve $\left(K_{b \text { sec }}^{\prime}\right)$ and the initial bond stiffness $\left(K_{b e}\right)$ (Eq. (1)). Initial bond stiffness is defined considering the maximum bond shear stress and the corresponding slip $\delta_{b}\left(K_{b e}=\tau_{b} / \delta_{b}\right.$ ). The secant bond stiffness in post-peak curve is determined likewise: the ratio of bond stress and the corresponding slip value (Fig. 2). The damage initiation is triggered by the slip that corresponds to maximum bond shear stress (Eq. (1)).

$D=\left\{\begin{array}{cc}0, & \delta \leqslant \delta_{b} \\ 1-\left(K_{b \sec }^{\prime} / K_{b e}\right), & \delta>\delta_{b}\end{array}\right.$

The bond shear stresses $\left(\tau_{s}\right)$ are subsequently calculated, depending on the value of the damage variable $D$ (Eq. (2)):

$\tau_{s}=\left\{\begin{array}{cc}\tau_{e}, & \tau_{e} \leqslant \tau_{b} \rightarrow D=0, \text { no damage } \\ (1-D) \tau_{e}, & \tau_{e}>\tau_{b} \\ \text { where } & \tau_{e}=K_{b e} \delta\end{array}\right.$

where $\tau_{e}$ is the bond stress component predicted by elastic bond stress-slip relation without damage, considering the initial bond stiffness $\left(K_{b e}\right)$ and the relevant slip $(\delta)$.

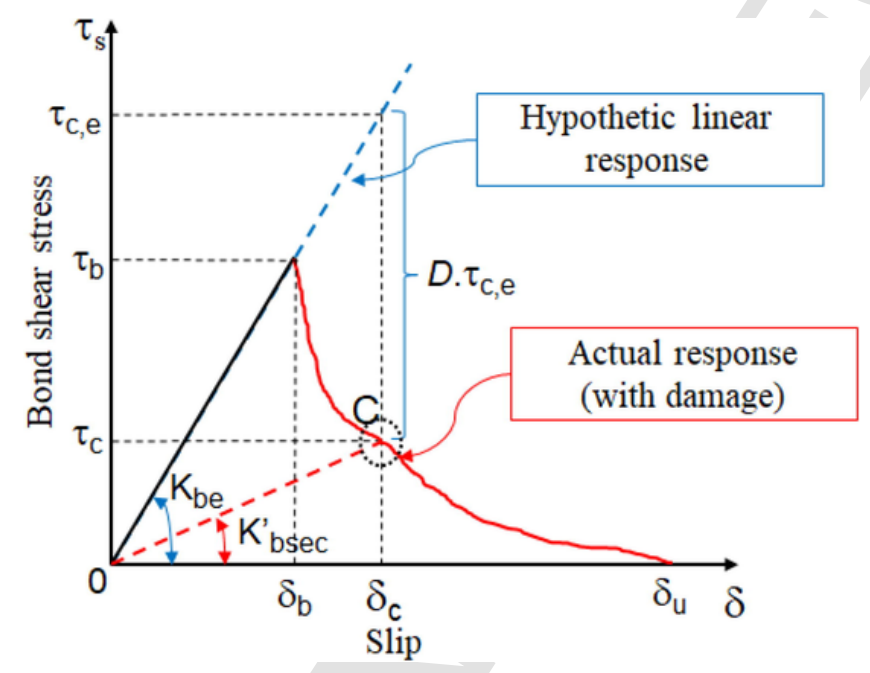

Fig. 2. Bond shear stress calculation based on the damage variable D: secant modulus-based damage model.

The graphical interpretation of Eq. (2) is shown in Fig. 2, considering the hypothetical linear bond response and the correction factor $(D$, $\left.\tau_{c, e}\right)$ for damage evolution in the post-peak branch.

Present method implies phenomenological approach for simulating bond behavior, as variable $D$ encompasses all parameters responsible for the bond deterioration, i.e. degradation of mechanical interlock, frictional resistance and adhesion. Similar strategy for the evolution of bond damage can be adopted for the bond stresses in the radial (normal) direction $\left(\sigma_{n}\right)$, when the corresponding bond normal stress-slip curves are used. Due to the lack of relevant experimental data, present study does not treat the evolution of bond damage in the normal direction.

\section{Experimental results overview}

In order to compare the two methods of bond consideration (indirect and direct) in the numerical analysis of FRP RC members, the experimental study of Schmitt and Pahn [43] was considered. It comprised flexural testing of thin GFRP RC slabs, which are typically used as precast panels for pavement or façade panels, as well as the external layers of sandwich members. GFRP as non-corrosive reinforcement allows maximal reduction of the concrete cover, which is particularly important in case of such thin members. Three slabs were selected for the numerical analysis to cover the complete range of thicknesses and failure modes observed in [43]. Main characteristics of the selected slabs are listed in Table 1.

All slabs had concrete cover of $10 \mathrm{~mm}$, whereas their length and width were $2200 \mathrm{~mm}$ and $300 \mathrm{~mm}$, respectively. The slabs had supports span of $2000 \mathrm{~mm}$, with two overhangs of $100 \mathrm{~mm}$. They were supported by one fixed and one movable metallic roller. Three-point test had load application point in the middle of the span, whereas four-point tests had $1200 \mathrm{~mm}$ distance between the loading points, with $400 \mathrm{~mm}$ of shear span at each end (Fig. 3).

Slabs were only longitudinally reinforced, with GFRP Schöck ComBAR ${ }^{\circledR}$ bars of diameter $8 \mathrm{~mm}$ [45]. Concrete mechanical properties were experimentally determined, and they were: $2.83 \mathrm{MPa}$, $37.7 \mathrm{MPa}$ and $23.6 \mathrm{GPa}$ for tensile splitting strength, compressive strength and modulus of elasticity, respectively.

The tests were displacement-controlled until slab failure, and the load vs stroke displacement curves were considered for comparison with numerical results. Stroke displacement corresponds to displacement of a slab along load application line. As reported in [43], failure occurred in the slab V02 due to concrete compressive failure, while

Table 1

Selected slabs for numerical simulation. Thickness, reinforcement and experimental failure load and mode [43].

\begin{tabular}{|c|c|c|c|c|c|}
\hline ID & $\begin{array}{l}\text { Slab } \\
\text { thickness } \\
{[\mathrm{mm}]}\end{array}$ & $\begin{array}{l}\text { Longitudinal } \\
\text { reinforcement }\end{array}$ & $\begin{array}{l}\text { Test } \\
\text { setup }\end{array}$ & $\begin{array}{l}\text { Failure } \\
\text { load } \\
{[\mathrm{kN}]}\end{array}$ & Failure mode \\
\hline V02 & 100 & $3 \emptyset 8 \mathrm{~mm}$ & $\begin{array}{l}\text { 3-point } \\
\text { bending }\end{array}$ & 26.9 & $\begin{array}{l}\text { Concrete } \\
\text { crushing }\end{array}$ \\
\hline V03 & 60 & $2 \emptyset 8 \mathrm{~mm}$ & $\begin{array}{l}\text { 4-point } \\
\text { bending }\end{array}$ & 13.9 & $\begin{array}{l}\text { Longitudinal } \\
\text { crack failure }\end{array}$ \\
\hline V10 & 40 & $3 \varnothing 8 \mathrm{~mm}$ & $\begin{array}{l}\text { 4-point } \\
\text { bending }\end{array}$ & 7.6 & $\begin{array}{l}\text { Longitudinal } \\
\text { crack failure }\end{array}$ \\
\hline
\end{tabular}

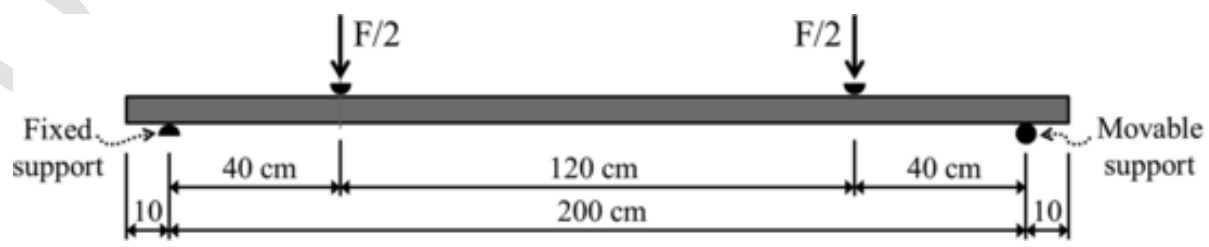

Fig. 3. GFRP RC thin slab test setup: 4-point bending. 
a shear crack occurred in the slabs V03 and V10, and was followed by a longitudinal crack alongside reinforcement at the moment of failure.

\section{Analytical predictive methods proposed by design guidelines}

For the sake of comparison with numerical modelling, the selected experimental tests were assessed by design guidelines, estimating the type of failure and corresponding failure load. ACI440.1R-15 guidelines [23], accounting for the debonding of FRP bars in flexure, were considered appropriate for this calculation. All slabs selected for this study had reinforcement ratio bigger than the balanced one. Therefore, they could theoretically fail in concrete crushing. Additionally, failure could be consequence of bar debonding. For both failure modes, ACI440.1R-15 guidelines provide formulas for the calculation of normal stress in reinforcement necessary for the failure occurrence. For this initial calculation, the maximum concrete compressive strain $\left(\varepsilon_{\mathrm{cu}}\right)$ was assumed equal to 0.0035 . Additionally, shear failure mode and corresponding failure load were also controlled. Since shear strength of members without shear reinforcement is significantly underestimated by ACI guidelines, CSA (Canadian Standards Association) S806-12 [46] and design approach of Guadagnini et al. [47] were used for the calculation of shear capacity [48]. The latter approach applied to Eurocode 2 rules and included in fib bulletin 40 [4] was used. Relevant calculations are presented in Table 2 .

Considering the shear failure mode (Table 2), it seems that none of the slabs was critical for shear. Analytical solutions predict concrete crushing failure for slabs V02 and V10, while V03 is supposed to fail due to debonding (Table 2). Analytical prediction is matching the experimentally recorded failure modes in case of slabs V02 and V03 (Table $1)$.

\section{FEM modelling strategy}

The numerical simulation of experimental test results was performed by the FEM (Finite Element Method) using the software Abaqus [40]. Constitutive model of the materials and the bar-concrete interface model, as well as the discretization details, are summarized in this section.

\subsection{Material and interface modelling}

\subsubsection{Concrete constitutive model}

Constitutive behavior of concrete was modelled using concrete damage plasticity (CDP) model implemented in Abaqus [40]. CDP parameters are adopted as follows: flow potential eccentricity $\epsilon=0.1$, the ratio of initial equibiaxial compressive yield stress to initial uniaxial compressive yield stress $\sigma_{b 0} / \sigma_{c 0}=1.16$, the ratio of the second stress invariant on the tensile meridian to that on the compressive meridian $K_{c}=0.67$, viscosity parameter $\mu=0$ [40]. The dilation angle $\psi$ was assumed to be $38^{\circ}$ according to the concrete compressive strength [49]. Compressive cylindrical strength of concrete is adopted as reported by experimental measurements $\left(f_{c m}=37.7 \mathrm{MPa}\right.$ ), while the tensile strength is estimated from experimental indirect tensile test measurements, namely the splitting tensile strength $\left(f_{c t, s p}=2.83 \mathrm{MPa}\right)$. According to fib Model Code 1990 , the conversion factor to obtain the mean axial tensile strength is 0.9 , therefore $f_{c t m}=0.9 f_{c t, s p}=2.55 \mathrm{MPa}[1]$

\section{Table 2}

Failure load $[\mathrm{kN}]$ corresponding to relevant failure modes and standards $\left(\varepsilon_{\mathrm{cu}}=0.0035\right)$.

\begin{tabular}{lllll}
\hline & ACI440.1R-15 & & CSA S806-12 & fib (2007) \\
\hline ID & Concrete crushing & Debonding & Shear failure & \\
\hline V02 & 20.3 & 30.6 & 31.4 & 42.4 \\
V03 & 15.8 & 13.9 & 17.5 & 24.4 \\
V10 & 7.3 & 11.8 & 11.7 & 19.1 \\
\hline
\end{tabular}

. Moreover, the effect of shrinkage on tensile strength (and behavior) of concrete was considered and it will be explained subsequently along with different concrete tensile models adopted. Poisson's ratio of concrete was 0.2 , whereas concrete modulus of elasticity $\left(E_{c}\right)$ was taken as experimentally measured $23.6 \mathrm{GPa}$.

The CDP model of concrete allows visualization of damage assuming that cracking initiates at points where the compressive (or tensile) equivalent plastic strain is greater than zero. This is used for the representation of damage pattern. The limit strain level, above which the concrete is considered completely cracked or crushed, was selected based on the corresponding concrete models and the size of finite element mesh. 5.1.1.1. Tensile behavior of plain concrete Plain concrete model was used for the simulations including the bond model between FRP bar and concrete. Tensile behavior of concrete was modelled as linear up to $f_{c t m}$ (concrete tensile strength). Then, it is characterized by tension softening that was modelled using the stress-crack opening model, instead of stress-strain one, minimizing the mesh sensitivity when concrete cracking occurs [50]. The stress-crack opening law adopted herein is the one proposed in [51,52] (Fig. 4), which is characterized by nonlinear concrete softening given by Eq. (3).

$$
\begin{aligned}
\sigma_{c t}=f_{c t m}\left(\left(1+\left(c_{1} \frac{w}{w_{c}}\right)^{3}\right)\right. & \exp \left(-c_{2} \frac{w}{w_{c}}\right) \\
& \left.-\frac{w}{w_{c}}\left(1+c_{1}^{3}\right) \exp \left(-c_{2}\right)\right)
\end{aligned}
$$

where, $\sigma_{c t}$ and ware concrete post-cracking stress and its corresponding crack opening value, respectively. $c_{1}$ and $c_{2}$ are experimental best-fit parameters equal to 3 and 6.93 , respectively, while $w_{c}=5.136 \frac{G_{f}}{f_{c t m}}$ is the crack opening value at which the stress drops to $0 . G_{f}$ is concrete tensile fracture energy that is calculated according to fib Model Code 1990, taking $8 \mathrm{~mm}$ as the maximum aggregate size, reported in the experimental results.The main reason for adopting this model instead the one in fib Model Code 1990 [1] is avoiding the sharp change of the slope in latter one (Fig. 4). The former allows achieving better convergence of the FE model after the first crack in the beam, when the load is being transferred from the cracked zone of concrete to the bars. The effect of shrinkage on tensile behavior of concrete was considered since it could noticeably decrease the cracking resistance of RC members. Shrinkage strain developed in concrete was assumed using the model proposed by Gilbert [53]. The period between concrete casting

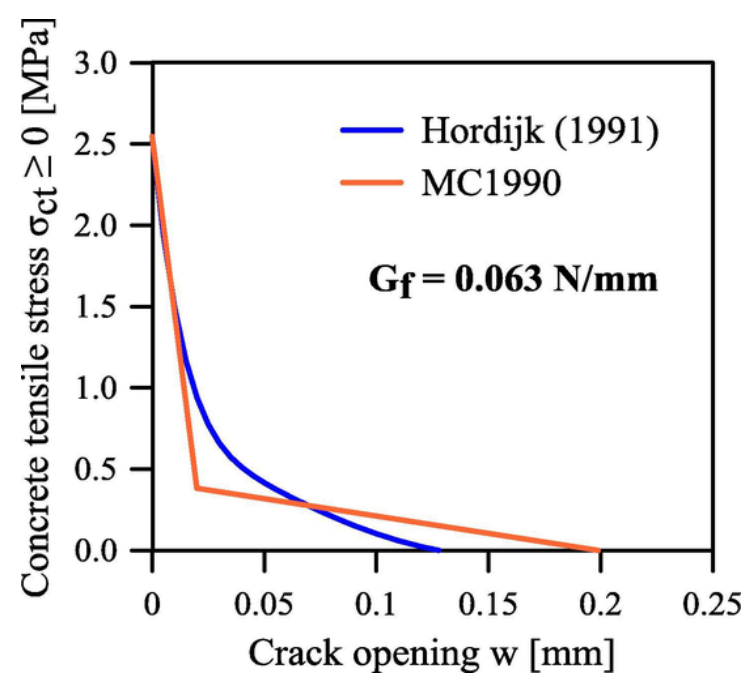

Fig. 4. Post-cracking stress-crack opening model of concrete: Comparison of Hordijk (1991) [52] and Model Code 1990 proposals. 
and testing of slabs was selected equal to 30 days. The final drying basic shrinkage strain was assumed as $1000 \cdot 10^{-6}$, whereas parameter $\mathrm{k}_{4}$ was taken equal to 0.65 (interior environment) [53]. For the calculation of hypothetical thickness, the portion of the section perimeter exposed to the atmosphere was taken as $300 \mathrm{~mm}$ (upper slab edge). So-obtained shrinkage strain was introduced into FE model before mechanical loading [54]. This was attained by imposing the temperature change in concrete, necessary for the same strain to occur. Coefficient of thermal expansion was set to $1 \cdot 10^{-5}$.

5.1.1.2. Tensile behaviour of reinforced concrete Pre-peak behavior of reinforced concrete was modelled as the plain one. Post-peak tensile behavior was modelled using the tension stiffening approach, which compensates the assumption of perfect bond with no slip between FRP bar and concrete, implemented in these simulations. The selected tension stiffening model was by Bischoff and Paixao [26], suitable for concrete members reinforced with FRP bars. It is characterized by tension stiffening parameter beta $(\beta)$ that is the ratio between average tensile stress carried by the cracked concrete $\left(f_{c t, c r}\right)$ and tensile strength $\left(f_{c t m}\right)$, $\beta=f_{c t, c r} / f_{c t m}$. Parameter $\beta$ decreases exponentially with the increase of average member strain $\left(\varepsilon_{m}\right)$ (Eq. (4)).

$\beta=\exp \left[-1100\left(\varepsilon_{m}-\varepsilon_{c r}\right)\left(E_{b} / 200\right)\right]$

In Eq. (4), $\varepsilon_{c r}$ is the concrete strain at cracking and $E_{b}$ is the elastic modulus of the reinforcing bar (in GPa). Bischoff and Paixao model is given as a stress-strain formulation, calibrated on axial tests of concrete ties reinforced with FRP bars. The stress-strain formulation of concrete tensile behavior is not recommendable for FE simulations, since being strongly dependent on the selected mesh size and geometry in this case. Therefore, in the present numerical simulations, stress-crack opening law was obtained by multiplying the average member strain $\left(\varepsilon_{m}\right)$ by the average crack spacing obtained from tested concrete ties in [26] Eq. (5). $s_{m}$ represents in this case the crack bandwidth.

$w_{m}=s_{m} \varepsilon_{s, m}=s_{m} \varepsilon_{m}$

In Eq. (5), $w_{m}$ is average crack width, that is, the crack opening, whereas $\varepsilon_{s, m}$ is average strain in the reinforcing bar (equal to $\varepsilon_{m}$ ) [6]). The given assumption is certainly a simplified solution. Eq. (5) is valid for the stabilized crack pattern, whereas here it has been used for the whole range of post-cracking concrete response, including crack development phase as well. However, reaching the stabilized crack phase, the assumption and the estimation of the crack opening becomes more correct. So-obtained stress-crack opening law was adopted for simulation of the post-peak tensile behavior of reinforced concrete. The stress-stain law was then assigned to each finite element independently, considering its characteristic element length, $l_{c h}=\sqrt[3]{V}$ (being $V$ the finite element volume) .Moreover, the tension stiffening model [26] was applied on the effective area of concrete in tension $\left(A_{c, e f f}\right)$. In case of flexural members, $A_{c, \text { eff }}$ was assumed as given in Model Code 1990 [1] (Fig. 5).In Fig. 5, $\phi$ is diameter of the bar, $h$ is thickness of the slab and $x$ is depth of the concrete compression zone. The neutral axis position was calculated analytically from the beginning of loading until failure, and the average value of neutral axis between the uncracked and the section at failure was used for the estimation of $A_{c, \text { eff }}$. In FE model, the tension stiffening concrete law was as-

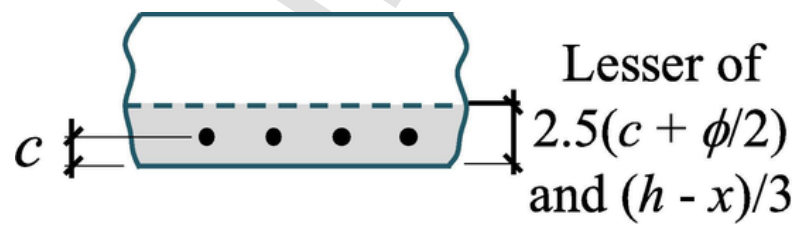

Fig. 5. The effective concrete area in tension [1]. signed to the relevant effective area of the slab, while the rest of the concrete body was considered as plain concrete.As for the shrinkage influence on tension stiffening law, the concrete tensile strength was decreased by the residual stress in concrete $\left(f_{\text {res }}\right)$ that develops due to the embedded reinforcement that restrains shrinkage. It is calculated as suggested by Scanlon and Bischoff [55], based on the work of Gilbert [56] (Eq. (6)).

$f_{\text {res }}=\frac{E_{b} \rho(d / h)(1+6 \xi) \varepsilon_{s h}}{1+\bar{n} \rho(d / h)\left(1+12 \xi^{2}\right)}$

In Eq. (6), $\rho$ is the reinforcing ratio, $d / h$ is the ratio of effective depth of reinforcement and beam height (slab thickness), $\xi$ is the eccentricity factor ( $\xi=d / h-0.5$ for a rectangular section), $\varepsilon_{s h}$ is the free shrinkage strain (calculated according to Gilbert [53]), $\bar{n}$ is the age-adjusted long term modular ratio, which is used here only as modular ratio, that is the ratio of modulus of elasticity of bar and concrete, since long term effects were not considered. Finally, the resulting concrete tensile strength is estimated as $f_{c t, s h}=f_{c t m}-f_{\text {res }}$. In addition, the area under post-peak tension stiffening curve was reduced as a consequence of shrinkage. The experimental value of factor beta $\left(\beta_{\exp }\right)$ was obtained from the equation given in [6], considering the developed shrinkage strain.

$\beta_{\exp }=\frac{\beta+[n \rho /(n \rho+1)]\left(\varepsilon_{s h} / \varepsilon_{c r}\right)}{1+[n \rho /(n \rho+1)]\left(\varepsilon_{s h} / \varepsilon_{c r}\right)}$

In Eq. (7), $n$ is modular ratio (ratio of modulus of elasticity of bar ( $E_{b}$ ) and concrete $\left(E_{c}\right)$ ) and $\rho$ is reinforcing ratio (ratio of steel $\left(A_{r}\right)$ and concrete areas $\left(A_{c}\right)$ ). In the case of flexural members, the concrete area was substituted by the effective tensile concrete area $\left(A_{c, \text { eff }}\right)$, thus, instead of $\rho$, the effective reinforcing ratio $\left(\rho_{\text {eff }}=A_{r} / A_{c, \text { eff }}\right)$ was used in Eq. (7) [6].Thus, the shrinkage influence was simulated in the effective concrete area by modifying the tensile parameters of RC tension stiffening model. Accordingly, the plain concrete model, employed in perfect bond simulations, was modified for the shrinkage influence by subtracting the residual stress in concrete $\left(f_{\text {res }}\right)$ (Eq. (6)) from its tensile strength $\left(f_{c t, s h}=f_{c t m}-f_{\text {res }}\right)$, whereas the fracture energy remained unchanged.

5.1.1.3. Compressive behavior of concrete Compressive behavior of concrete was modelled according to the recommendations of Kratzig and Polling [57]. It is linear elastic up to $0.3 f_{\mathrm{cm}}$ (30\% of concrete compressive strength), followed by the hardening behavior up to $f_{c m}$. The hardening is characterized by nonlinear stress-strain law as proposed by Model Code 1990 [1] (Eq. (8)).

$\sigma=\frac{E_{c i} \frac{\varepsilon}{f_{c m}}-\left(\frac{\varepsilon}{\varepsilon_{c m}}\right)^{2}}{1+\left(E_{c i} \frac{\varepsilon_{c m}}{f_{c m}}-2\right)\left(\frac{\varepsilon}{\varepsilon_{c m}}\right)} f_{c m}$

In Eq. (8), $\varepsilon_{c m}$ is the strain accompanying the failure stress $f_{c m}$, assumed equal to 0.0022 according to Model Code 1990 [1], whereas modulus $E_{c i}$ is given by Eq. (9), as proposed by [57].

$E_{c i}=\frac{1}{2 E_{c}}\left(\frac{f_{c m}}{\varepsilon_{c m}}\right)^{2}-\frac{f_{c m}}{\varepsilon_{c m}}+\frac{3}{2} E_{c}$

Post-peak behavior of concrete in compression, similarly to the one in tension, is characterized by softening accompanied by localization $[58,59]$. Namely, the compression tests carried out on specimens of different height have shown that softening cannot be considered independently of the specimen dimension. Accordingly, in FE analysis, this branch of the stress strain curve depends on the crushing energy $\left(G_{c l}\right)$ and the characteristic finite element length $\left(l_{c h}\right)$. It is defined by Eq. 
(10) $[57,60]$.

$\sigma=\frac{1}{\frac{2+\gamma_{c} f_{c m} \varepsilon_{c m}}{2 f_{c m}}-\gamma_{c} \varepsilon+\frac{\gamma_{c}}{2 \varepsilon_{c m}} \varepsilon^{2}}$

Parameter $\gamma_{c}$ controls the area under stress-strain curve, depending on $G_{c l}$ and $l_{c h}[57]$ :

$\gamma_{c}=\frac{\pi^{2} f_{c m} \varepsilon_{c m}}{2\left[\frac{G_{c l}}{l_{c h}}-\frac{1}{2} f_{c m}\left(\varepsilon_{c m}(1-b)+b \frac{f_{c m}}{E_{c}}\right)\right]^{2}}$

In Eq. (11), the scalar parameter $b$, which splits inelastic strains into plastic and damaging parts [57], was neglected due to absence of cyclic loading.Concrete crushing energy was assumed as $G_{c l}=15 \mathrm{~N} / \mathrm{mm}$, being the average value from different experimental testing [59].

\subsubsection{GFRP constitutive model}

GFRP material is modelled as linear elastic transversally isotropic. Its volumetric content of fibers and matrix was $75 \%$ and $25 \%$ respectively. The elastic constants of constituents (fibers and matrix) are assumed following the recommendations of fib Bulletin 40 [4]. The orientation of fibers in matrix is shown in Fig. 6, where 1 is the bar longitudinal axis, and 2 and 3 are transversal axis. The elastic constants of the composite material are taken from producer's datasheet [45] (GFRP modulus of elasticity in the longitudinal direction $E_{1}=60 \mathrm{GPa}$ ), and predicted by the rule of mixture and the Chamis' formulae [61], namely: modulus of elasticity in the transversal direction $E_{2}=E_{3}=18.8 \mathrm{GPa}$, shear modulus $G_{12}=G_{13}=G_{23}=7.01 \mathrm{GPa}$ and Poisson's coefficients $\mu_{12}=\mu_{13}=0.26$, $\mu_{23}=0.34$.

\subsubsection{Interface model}

To set the interface model in Section 2, the experimental local bond-slip law (Fig. 7) was adopted as measured by eccentric pull-out tests [42], having the same concrete cover (10 mm), the same GFRP bar (Schoeck $\emptyset 8$ ) and similar concrete quality as modelled slabs. The bond law was directly included into numerical analysis, to simulate the slip between bar and concrete and its effects during the loading of slabs. The nonlinearity in the bond interface properties was simulated using cohesive finite elements [40], in combination with parameters of post-peak response for the damage evolution according to the model in Section 2. For the lack of experimental measurements, the damage evolution in normal (radial) direction was not considered, by assuming very high damage initiation value in normal direction.

\subsection{Geometry, boundary conditions and FE discretization}

For decreasing the calculation time, the geometry of slabs was simplified by modelling only one quarter, using two planes of symmetry. Bar geometry was modelled as unribbed cylindrical body, since all interface effects (due to the presence of ribbed surface layout) are simulated using the model described in Section 2. The interface was represented as a hollow cylinder with thickness of $0.001 \mathrm{~mm}$. In case of per-

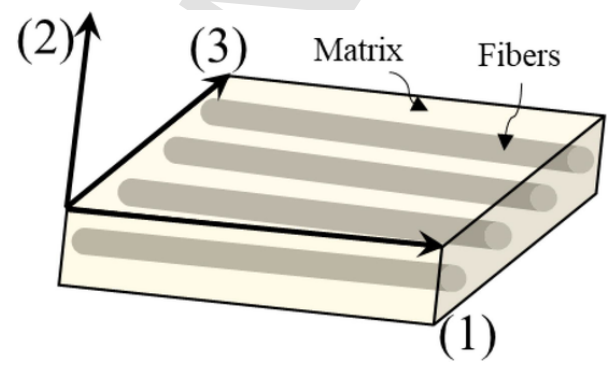

Fig. 6. The reference frame for orientation of fibers in GFRP bar.

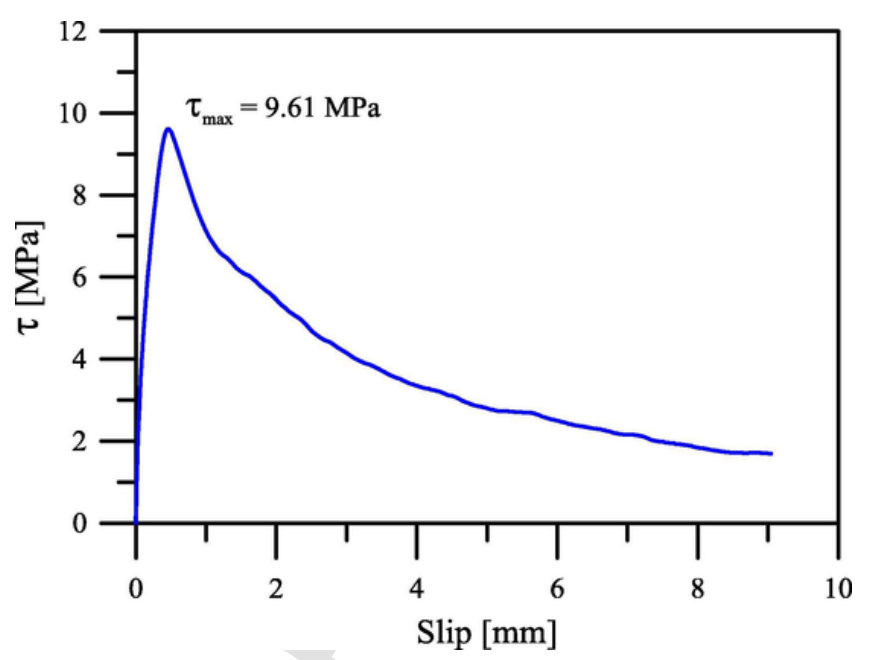

Fig. 7. Bond shear stress - loaded-end slip law, experimental data [42].

fect bond simulation, bar and concrete adjacent elements shared the same nodes.

In the numerical simulation the temperature corresponding to the shrinkage strain was first applied, then the loading conditions were modelled as displacement-controlled, applied on the top surface of the slab along the lines of the load application.

Concrete and bar were modelled with 3D solid hexahedral elements C3D8R, with reduced integration, whereas the cohesive finite elements COH3D8 were used for the interface. FE discretization was based on adequate representation of curved surfaces (bar, and concrete around it), the proper subdivision of thin concrete cover and the characteristic length related to microstructure of concrete. According to Bazant and Oh [15], the characteristic length is three times the maximum aggregate size. It presents the minimum acceptable dimension for the representative volume, that is, for continuum smoothing of the randomly inhomogeneous material. In present case, it was $24 \mathrm{~mm}$. Accordingly, the length of the elements along the slab load-transferring-axis was selected equal to 25, 33.3 and $50 \mathrm{~mm}$, for three different mesh subdivisions. The element lengths were smaller than the maximum one suggested by [15] that is $\frac{1}{2} \cdot \frac{2 \cdot G_{F} \bullet E_{c}}{f_{c t m}{ }^{2}} \approx 230 \mathrm{~mm}$. Instead, in cross-sectional plane, the subdivision was dependent on the first two parameters mentioned above (adequate representation of curved surfaces and proper subdivision of thin concrete cover) and it resulted in three mesh subdivisions, corresponding to the longitudinal one, so to obtain homothetic mesh refinement. Three different meshes, coarse, medium and fine, for slab V03, are presented in Fig. 8. The models had 2816, 9900 and 22,528 finite elements, respectively. The number of finite elements for slab V02 was $3450,11,385$ and 26,400, and 2508, 8910 and 20,064 for V10, respectively to the three mesh densities.

A refined mesh was applied in the zones where relatively high stress gradients are expected to develop (contact between bar and concrete, and through concrete cover thickness).

The same mesh topology was used for models including bond-slip law and the ones assuming perfect bond. In case of perfect bond simulations, the portion of cross section framed in red in Fig. 8, was corresponding to the effective concrete area in tension and its tensile behavior was modelled as the one of the reinforced concrete (Section 5.1.1). Tensile behavior of the remaining part of the cross section was modelled as plain concrete (Section 5.1.1).

\section{Results and discussion}

To assess the performance of the local bond-slip model for simulating the structural response of RC members with GFRP bars, in comparison with perfect bond model, the experimental outcomes for the 


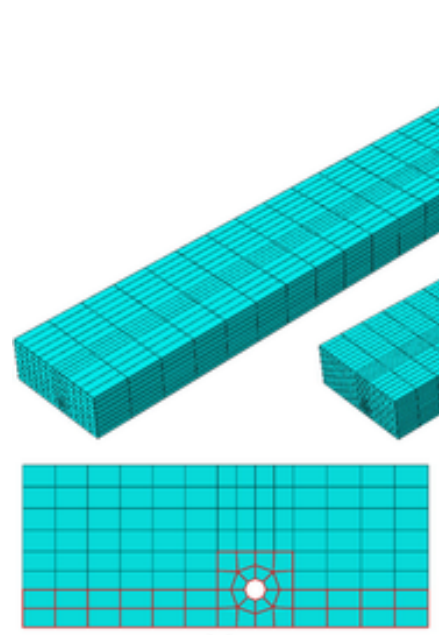

(a)

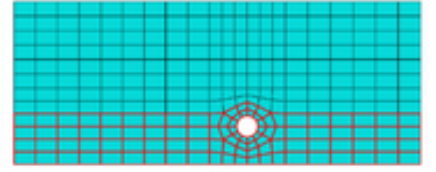

(b)

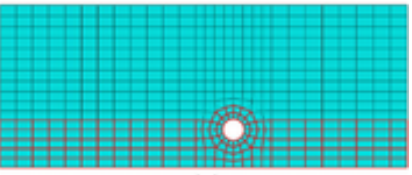

(c)

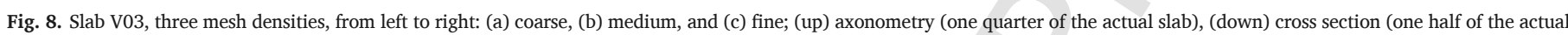

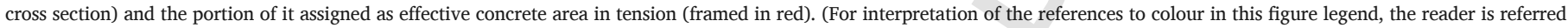
to the web version of this article.)

RC members geometry and test setup detailed in Section 3, were considered and compared to the outcome of the numerical analyses.

Failure mode and corresponding failure load, obtained by the experimental tests, ACI and fine mesh FE models (for perfect bond and bond slip law), are listed in Table 3.

The CDP model of concrete allows visualization of damage assuming significant values of equivalent plastic strain in uniaxial tension and uniaxial compression (PEEQT and PEEQ). Significant values in this case are selected as: PEEQ strain equal to 0.0022 (strain corresponding to compressive strength), and PEEQT corresponding to null post-peak tensile stress. PEEQT has two significant values for perfect bond simulations, one referring to tension stiffening model and the other referring to plain concrete model. Former is always higher due to higher capacity of reinforced concrete, thus it is selected as limit tensile strain level and it refers to the effective area of concrete in tension. Latter is designated by asterisk on the PEEQT legend (Figs. 14 and 18) and it refers to the upper part of the slab modelled as plain concrete. Above these limit tensile strain levels, the concrete is considered completely cracked, whereas the limit strain in compression is the one that corresponds to the initiation of crushing. Described representation of the damage pattern refers to all strain maps presented in this paper. Graphics are accompanied with the symmetry symbols, and dashed lines (and triangles) denoting support position. Loading is in the middle of the slab in case of V02 (three-point bending), whereas it is denoted with arrows (and dashed lines) in case of slabs V03 and V10 (four-point bending).

\subsection{Slab V02}

The first slab (V02) had thickness of $100 \mathrm{~mm}$ and failed in concrete crushing. The FE simulation results, compared to the experimental output, are given in Fig. 9. In these diagrams, and the following ones, ' $\mathrm{C}$ ' stands for coarse, 'M' for medium, and ' $\mathrm{F}$ ' for fine mesh.

Perfect bond model showed negligible dependency on the mesh density (Fig. 9a). Only the fine mesh model demonstrated clearly the failure due to concrete crushing at load level of $29.6 \mathrm{kN}$. With densification of the mesh the structural response becomes slightly stiffer (Fig. 9a), as a consequence of the mesh with reduced integration elements [62]. The cracking load is overestimated, whereas the stiffness corresponds perfectly to the experiment. The failure load level is overestimated approximately for the same value as the cracking one, and this eventually results in $10 \%$ higher failure load compared to experimental one (Table 3).

Fig. 10 gives the concrete compressive damage representation on the top slab surface for the three mesh densities of perfect bond model that yielded quite similar result.

Table 3

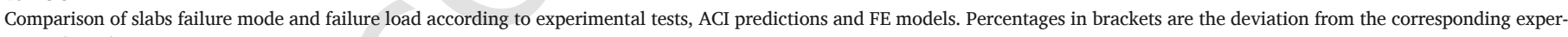
imental result.

\begin{tabular}{|c|c|c|c|c|c|}
\hline Slab ID & Property & Experimental & $\begin{array}{l}\text { ACI } \\
440.1 \mathrm{R}-15\end{array}$ & $\begin{array}{l}\text { FE model (perfect } \\
\text { bond, fine mesh) }\end{array}$ & $\begin{array}{l}\text { FE model (bond- } \\
\text { slip law, fine } \\
\text { mesh) }\end{array}$ \\
\hline \multirow[t]{2}{*}{ V02 } & FM & $\begin{array}{l}\text { Concrete } \\
\text { crushing }\end{array}$ & $\begin{array}{l}\text { Concrete } \\
\text { crushing }\end{array}$ & Concrete crushing & $\begin{array}{l}\text { Concrete } \\
\text { crushing }\end{array}$ \\
\hline & FL $[\mathrm{kN}]$ & 26.9 & 20.3 & $29.6(+10 \%)$ & $26.3(-2 \%)$ \\
\hline \multirow[t]{2}{*}{ V03 } & FM & $\begin{array}{l}\text { Longitudinal } \\
\text { crack failure }\end{array}$ & Debonding & $\begin{array}{l}\text { Concrete crushing/ } \\
\text { Debonding }\end{array}$ & Debonding \\
\hline & FL $[\mathrm{kN}]$ & 13.9 & 13.9 & $19.2(+38 \%)$ & $12.9(-7 \%)$ \\
\hline \multirow[t]{2}{*}{ V10 } & FM & $\begin{array}{l}\text { Longitudinal } \\
\text { crack failure }\end{array}$ & $\begin{array}{l}\text { Concrete } \\
\text { crushing }\end{array}$ & $\begin{array}{l}\text { Concrete crushing/ } \\
\text { Damage of concrete } \\
\text { along bars }\end{array}$ & $\begin{array}{l}\text { Concrete } \\
\text { crushing/Damage } \\
\text { of concrete along } \\
\text { bars }\end{array}$ \\
\hline & FL $[\mathrm{kN}]$ & 7.6 & 7.3 & $9.8(+29 \%)$ & $8.3(+9 \%)$ \\
\hline
\end{tabular}

*FM - Failure mode; FL - Failure Load. 


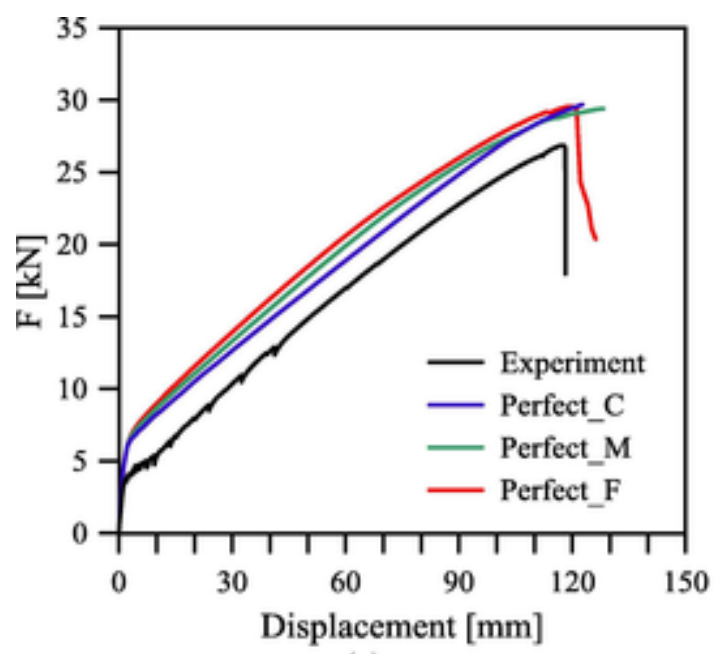

(a)

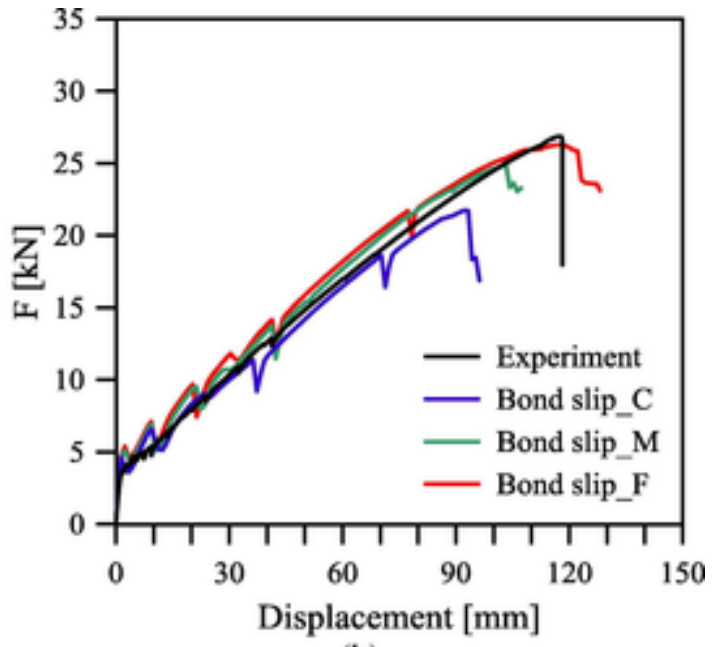

(b)

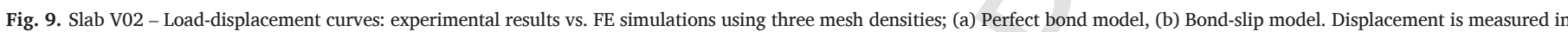
the middle of load application line.

\section{Perfect bond model, PEEQ}

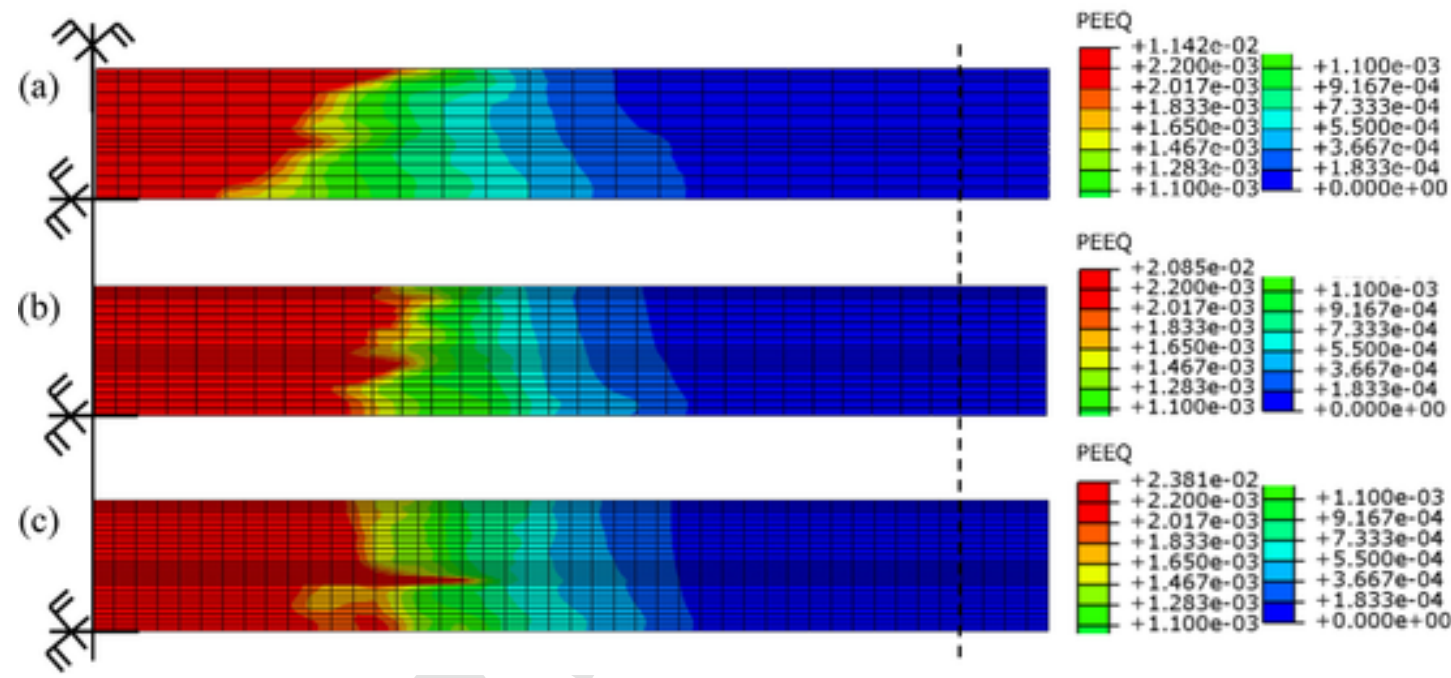

Fig. 10. Slab V02 - PEEQ strain map at failure, top slab view, perfect bond model: (a) coarse, (b) medium and (c) fine mesh.

Bond-slip model exhibited higher mesh dependency than the perfect bond one. Apart from slight increase of stiffness, the failure load level increased as well with the mesh refinement (Fig. 9b). The damage mode changed from splitting failure, for coarse mesh, to concrete compressive failure in combination with splitting, for fine mesh (Fig. 11). Fig. 11 shows the failure mode for coarse mesh model due to concrete cover splitting damage along the bar position, before the strain corresponding to compressive strength is reached at the top slab surface. This outcome changes as the mesh is becoming denser. The splitting still occurs, but after the concrete compressive capacity is exploited (Fig. 11d, e). Shear cracks, observed in the experiment (Fig. 12), become visible as damage in the fine mesh model (Fig. 11f). Opposite to perfect bond model, the cracking load was only slightly overestimated, and the overall numerical structural stiffness matched very well the experimental one (Fig. 9b). The failure load was in good agreement with the experimental one only for the fine mesh model.

Analytical solution proposed by ACI predicts, instead, the failure of the slab at the load level equal to $75 \%$ of the experimentally recorded (Table 3). It is mainly connected to the assumption of 0.0035 as the ultimate concrete compressive strain, whereas the concrete compres- sive capacity does not drop sharply, but gradually, at higher levels of strain, according to the concrete constitutive model employed in this study and described in Section 5.1.1. This extends the performance in compression, in comparison with conservative analytical predictions, and matches the experimental response of RC members. Preliminary understandings on the accuracy of the adopted concrete compressive constitutive model are detailed in [63].

\subsection{Slab V10}

Perfect bond model of the slab V10 (40 mm thickness) yielded higher failure load, and corresponding deflection of the slab, as the mesh was becoming denser (Fig. 13). All three meshes of perfect bond model overestimated the cracking load, while the medium and fine one predicted well the slope of experimental load-displacement diagram. Bond-slip models provided an overall accurate matching of the experimental response. Change of the slope of numerical diagrams occurred when compressive strain in concrete on the top slab surface reached the one corresponding to compressive strength (0.0022). The same change of diagram inclination is visible on the experimental re- 

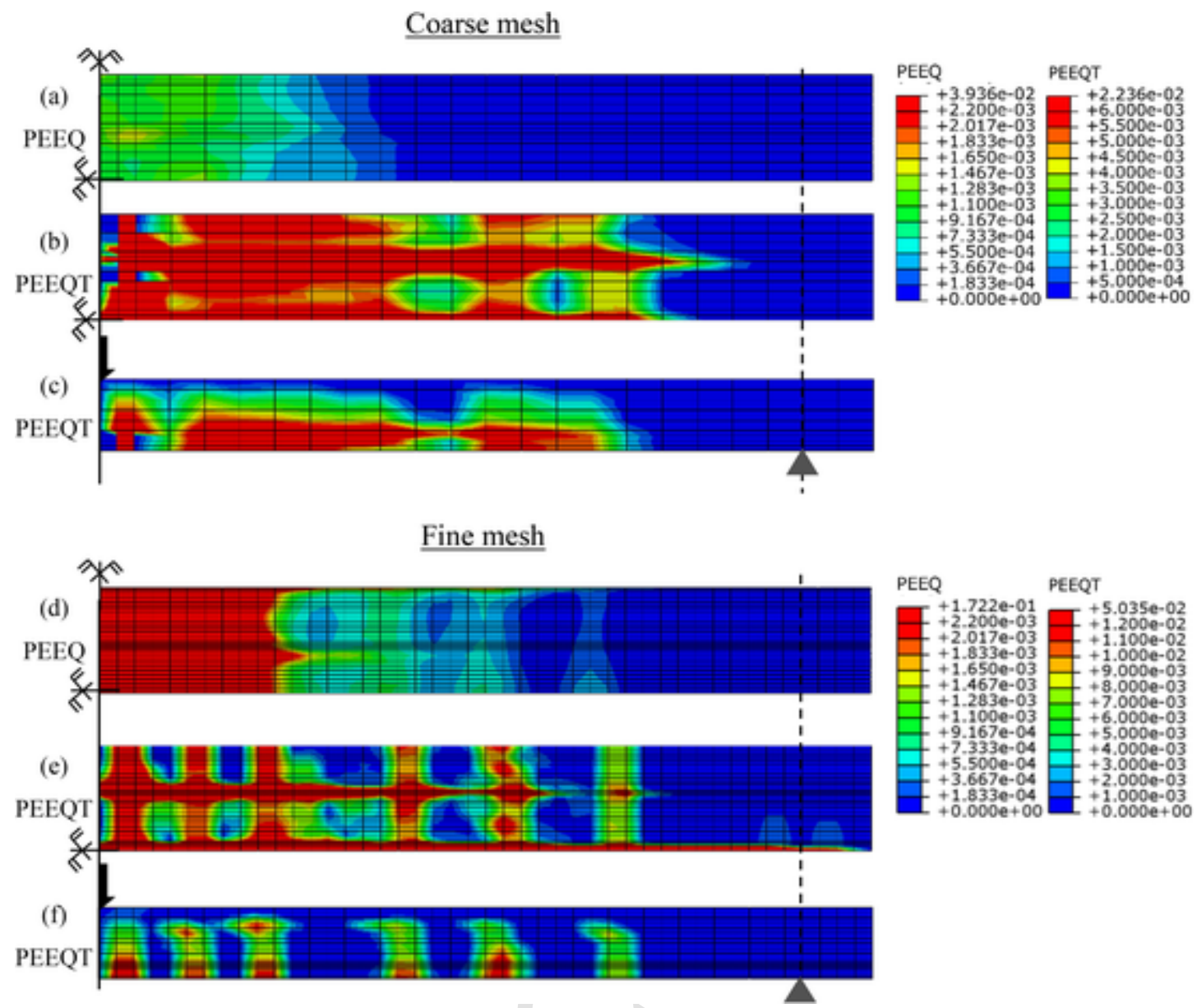

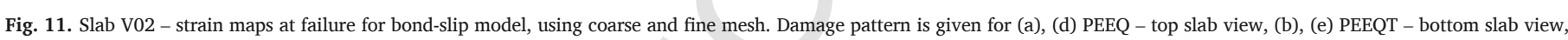
and (c), (f) PEEQT - side slab view.

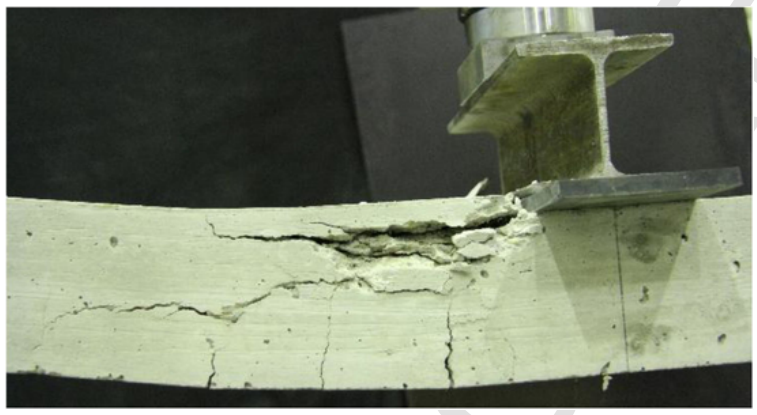

Fig. 12. Slab V02 - damage at failure (photo courtesy of authors [43]).

sponse and it is matched very well by the numerical curves of both bond approaches with medium and fine meshes. This slope change is visible in the behavior of this thin slab ( $40 \mathrm{~mm}$ thickness), due to very small compressive zone thickness, opposite to the slab V02, described previously. ACI code prognosed concrete crushing failure at load level of $7.3 \mathrm{kN}$ (assuming ultimate concrete compressive strain of 0.0035 ). The concrete crushing failure, initiated in numerical models, was followed by concrete damage spread longitudinally along the bar towards the top slab surface (Figs. 14 and 15). Figs. 14a and 15a depict crushed concrete in the constant bending moment zone (between load application points) on the top side of the slab. Subsequently, the concrete damage spreads along the outer bars, from the middle to the supports, at the moment of failure. Figs. $14 \mathrm{e}$, f and $15 \mathrm{~d}$, e show completely damaged concrete around the bar and cross-sectional deformed shape with the bar's tendency to longitudinally punch through the upper concrete layer. This type of failure mode is reported by the experimental test, denoting it as a 'disrupt crack failure because of bond failure' [43] (Fig. 16). In the present work, it is denoted as 'longitudinal crack failure' (Tables 1 and 3). In numerical simulations, it is appearing as damage concentrations along the bars on the top slab surface, and accompanying splitting damage on the bottom side (see Figs. 14 and 15).

\subsection{Slab V03}

When modelling the slab V03 (60 mm thickness), finer mesh led to slightly higher failure load and failure deflection compared to two other mesh sizes, for both bond models (Fig. 17). Cracking load was overestimated by perfect bond model and matched well by the bond slip one. Numerical member stiffness corresponds very well to the experimental result in all cases. In case of perfect bond simulation, coarse mesh model fails for premature crushing of concrete along the bar on the top slab surface, as the bar has tendency of longitudinal punching, similar to the numerical modelling of the slab V10. However, for medium and fine mesh models, concrete compressive capacity developed extensively before the concrete damage along the bar occurred (Fig. 18). This resulted in corresponding failure load that significantly overestimates (approximately 40\%, in case of fine mesh) the experimentally obtained one (Fig. 17a). Instead, the bond-slip model yielded correct failure mode (bar debonding) and matched the corresponding load level (Figs. 17b, 19). In this case, the concrete crushing initiated as well, but developed only locally and significantly less than in case 


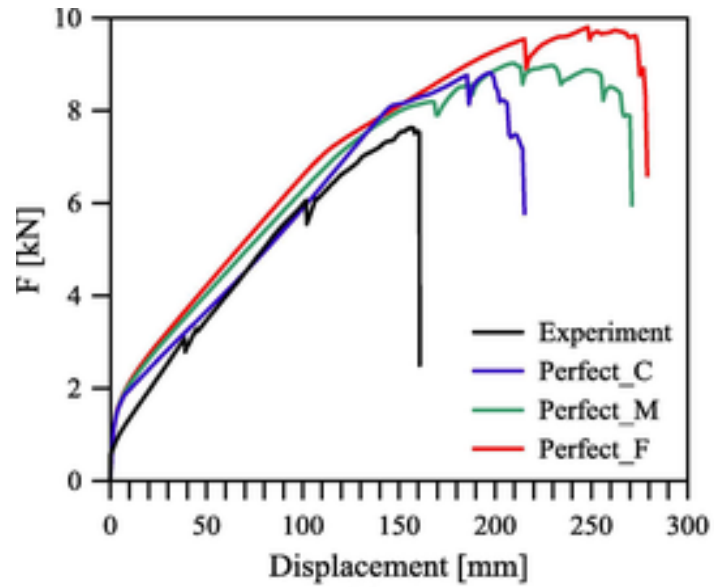

(a)

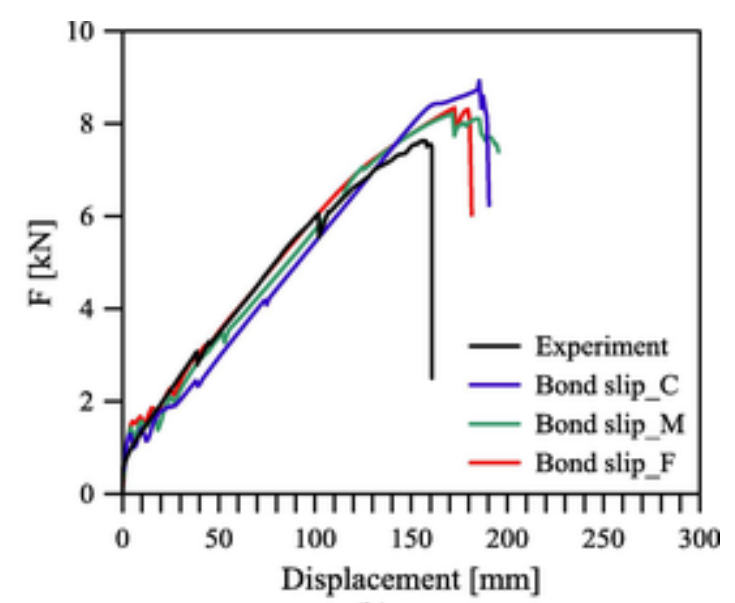

(b)

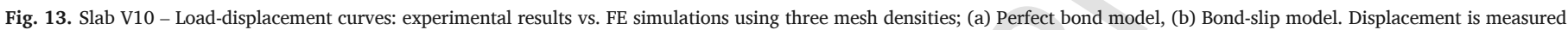
in the middle of load application line.

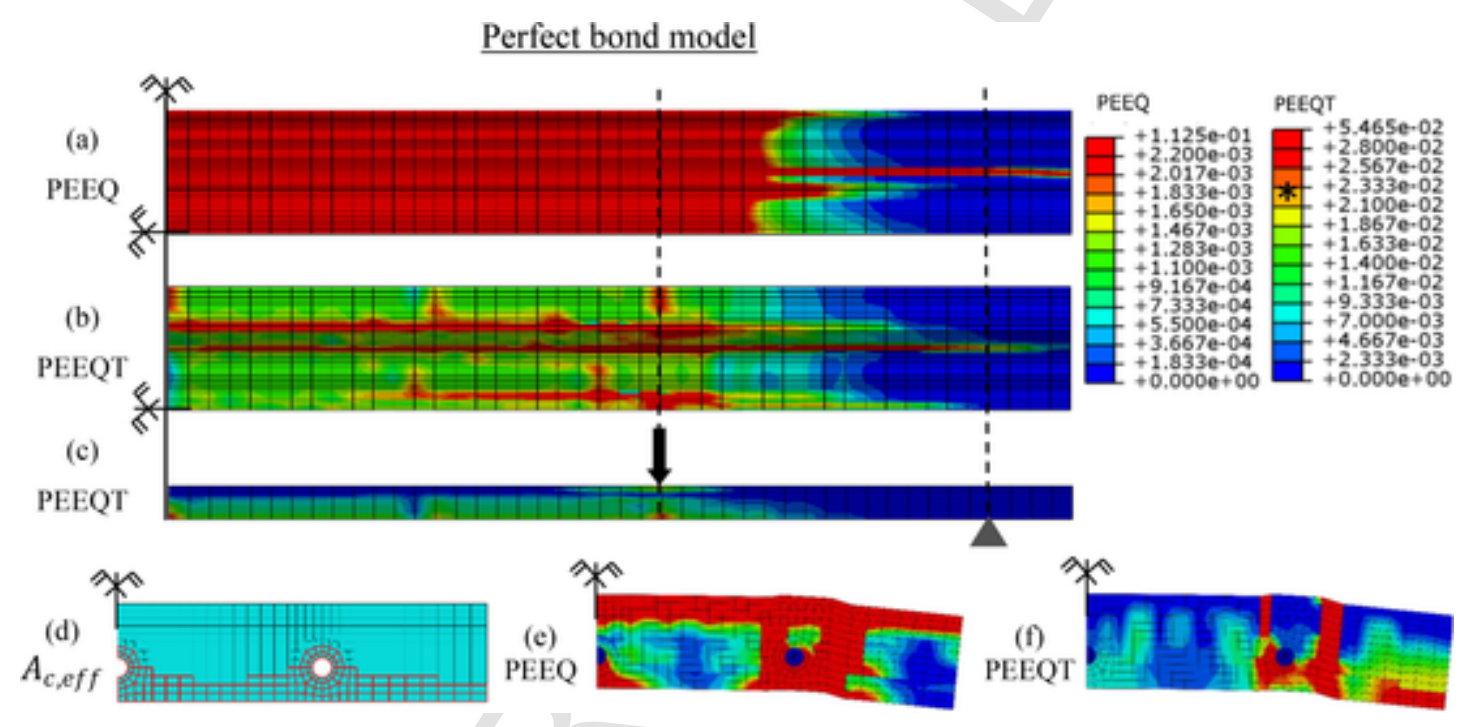

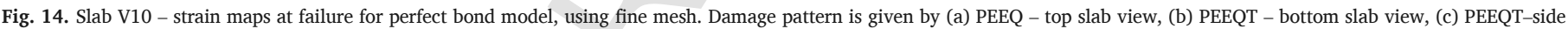

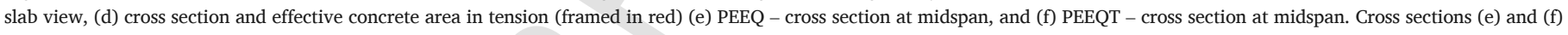
are given in deformed shape. (For interpretation of the references to colour in this figure legend, the reader is referred to the web version of this article.)

of a perfect bond (Fig. 19a). The reason is that perfect bond model used concrete tension stiffening constitutive law that helped bar in carrying the stress and delayed debonding, allowing concrete compressive stress to develop. It shows that using adopted tension stiffening model might overestimate the load carrying capacity of such thin concrete slabs reinforced with GFRP bars. Bond-slip model used in combination with plain concrete tensile law yielded correct simulation of the experimental test (Fig. 20). In perfect bond model, concrete damage developed on the top slab side along the bar, whereas in bond slip model it developed simultaneously at top and bottom surfaces. As for the analytical prediction, the ACI proposal matched the experimental and bond-slip simulation result.

\section{Discussion}

Mesh sensitivity analysis showed that with densification of the mesh the member strength remained the same or increased. The improvement of strength with the refinement of the mesh is related to the fact that the damage is expanded on a smaller volume, resulting in a delay of global failure and a higher failure load compared to coarser meshes. Apart from this, the failure mechanism of coarse meshes was often inaccurate, that is, premature failure of slabs due to damage of con- crete along the bar. Namely, finite elements were shaped so that the dimension along slab load-transferring axis was significantly longer than the element dimensions in slab cross-sectional plane. This created the ratio of 1:6 between the cross-sectional measures (that were approximately equal) and the longitudinal one. Such elongated shape of finite elements could create certain problems when modelling the concrete. In this study, concrete stress-strain compressive law was directly defined by user, whereas tensile law was inserted as a stress-crack opening relation, being transferred to stress-strain dependency by software. In both cases, the characteristic element length was used for these transformations, and it was calculated as a cubic root of FE volume $\left(l_{c h}=\sqrt[3]{V}\right.$ ). Considering the shape of finite elements, $l_{c h}$ gets a value in-between cross-sectional and longitudinal element dimension. Such condition led to premature failure of slabs due to longitudinal splitting damage, before their flexural capacity fully developed, as mentioned before. It caused wrong failure modes to develop when coarse meshes have been used. It is particularly visible in bond slip simulation of the slab V02 (bottom side longitudinal splitting) and perfect bond simulation of the slab V03 (top side longitudinal crushing). As shown in the study, this occurrence can be prevented when sufficiently fine meshes are used. 


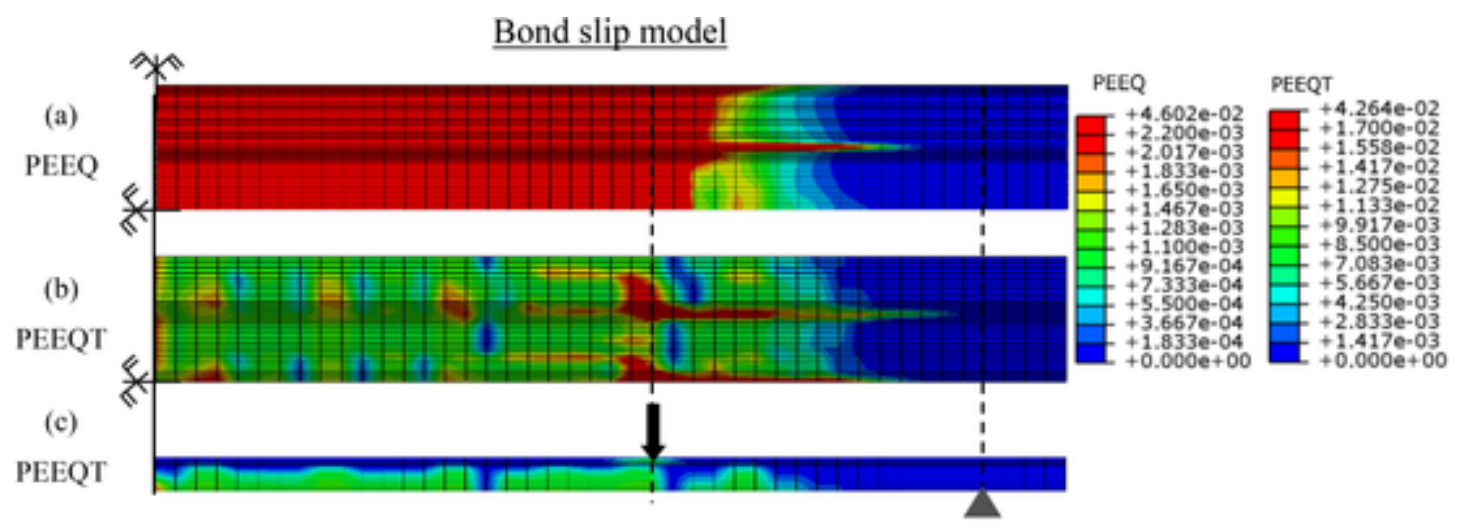

PEEQ

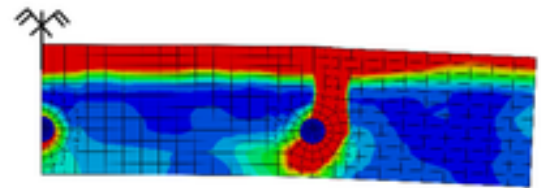

(e)

PEEQT

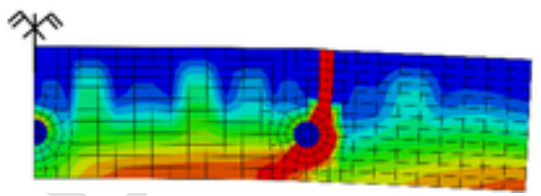

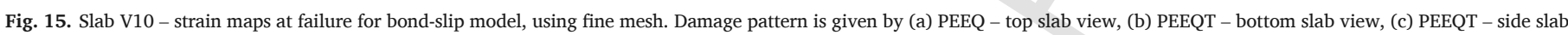
view, (d) PEEQ - cross section at midspan, and (e) PEEQT-cross section at midspan. Cross sections are given in deformed shape.

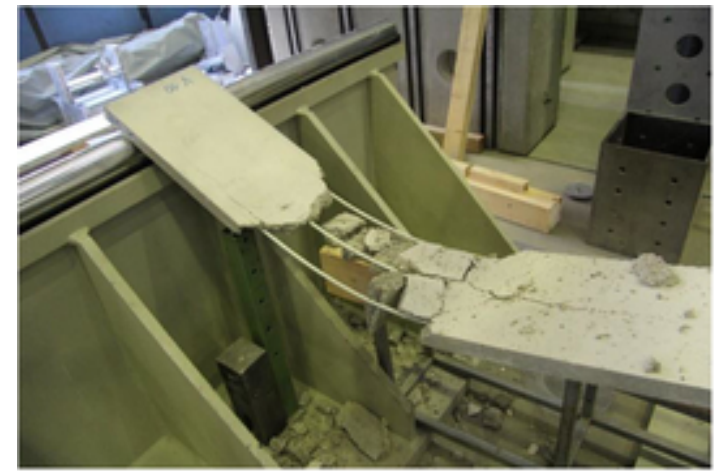

(a)

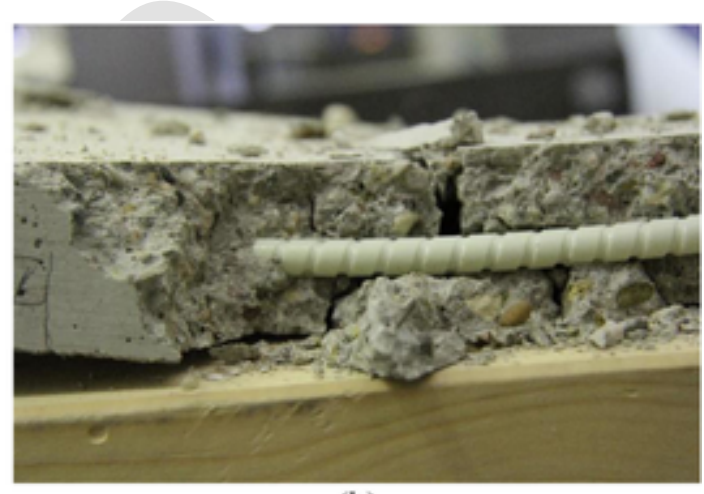

(b)

Fig. 16. Slab V10 - damage at failure: (a) slab at testing setup, (b) detail of embedded reinforcing bar (photo courtesy of authors [43]).

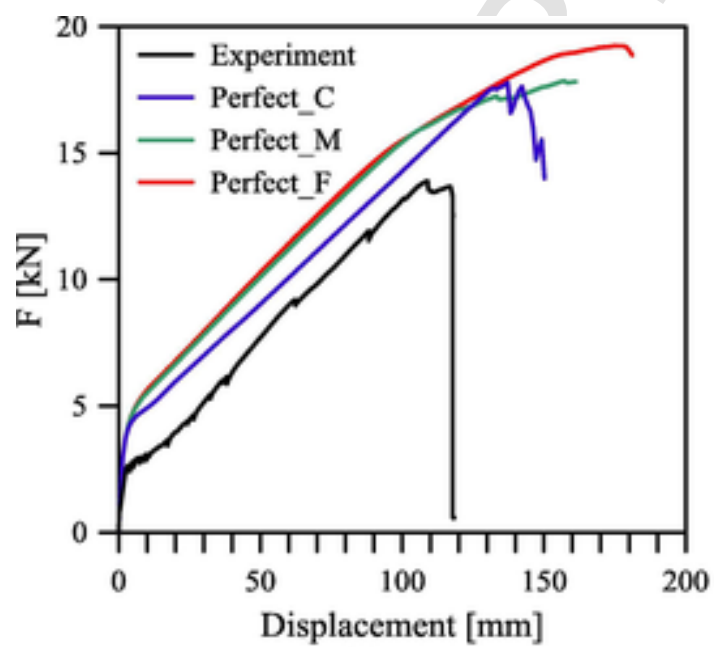

(a)

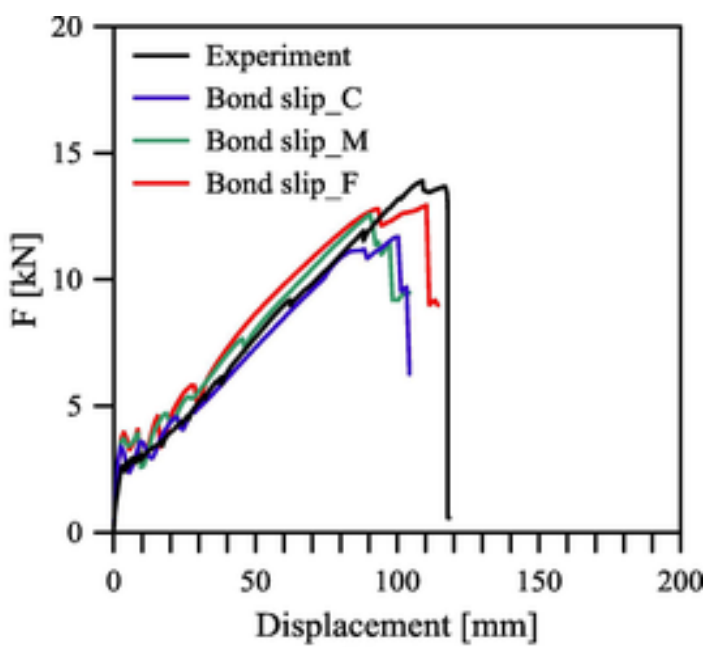

(b)

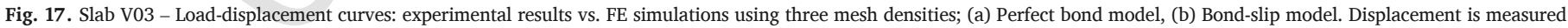
in the middle of load application line.

Another issue concerning the FE dimension is related to tension stiffening model used. Regularization of stress-strain law done in Section 5.1.1, related to the average crack spacing $\left(s_{m}\right)$, is valid only when finite elements have characteristic length equal or bigger than $s_{m}$ [64]. The average crack spacing equals approx. $140 \mathrm{~mm}$ in this case, and it is estimated as too high for the characteristic element 


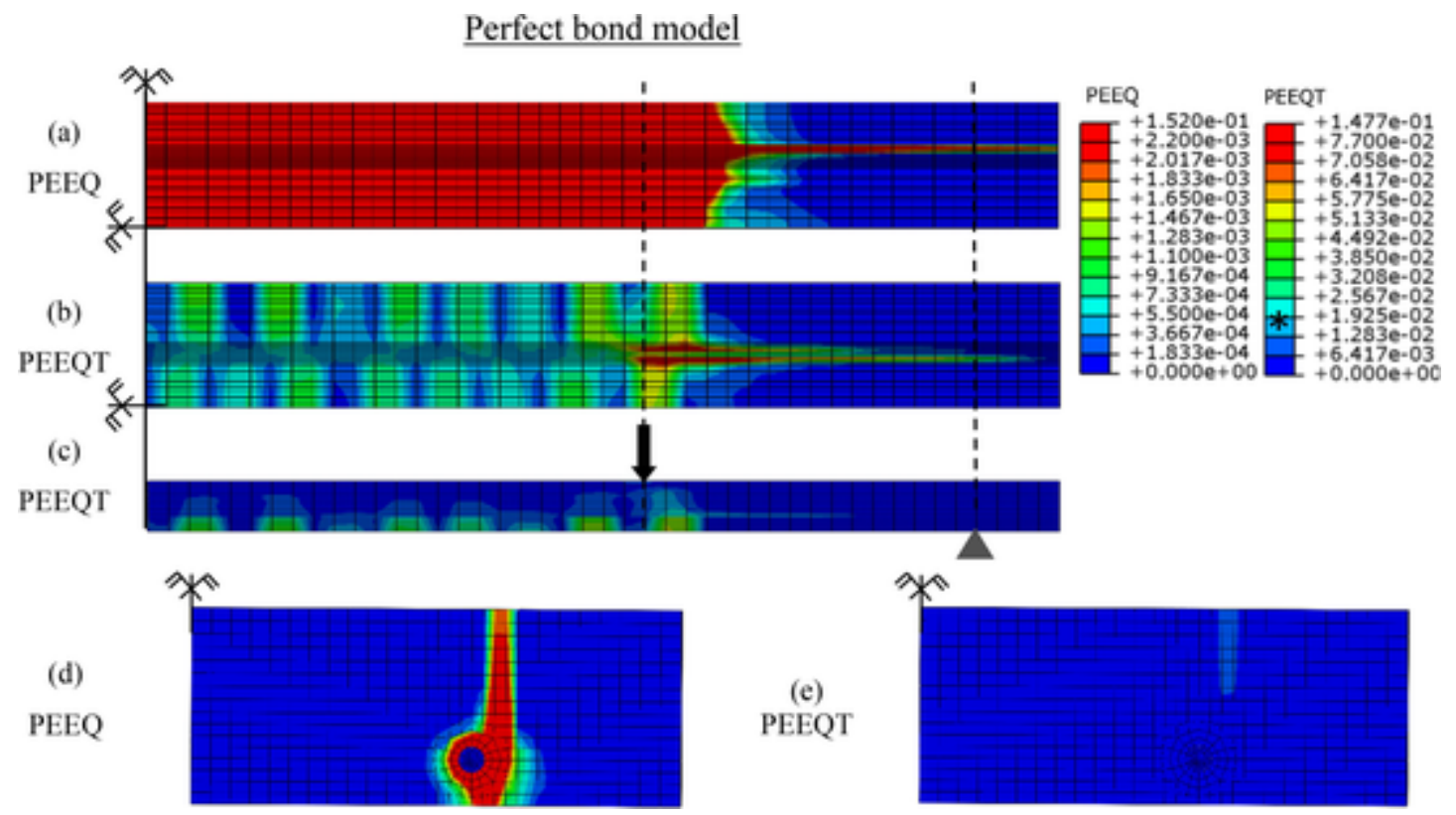

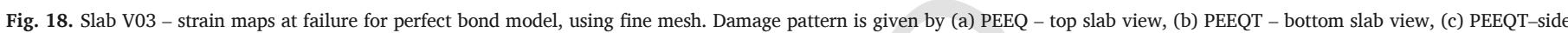
slab view, (d) PEEQ - cross section at the slab end, and (e) PEEQT - cross section at the slab end. Cross sections are given in deformed shape. $A_{c, e f f}$ for V03 is given in Fig. $8 \mathrm{c}$.

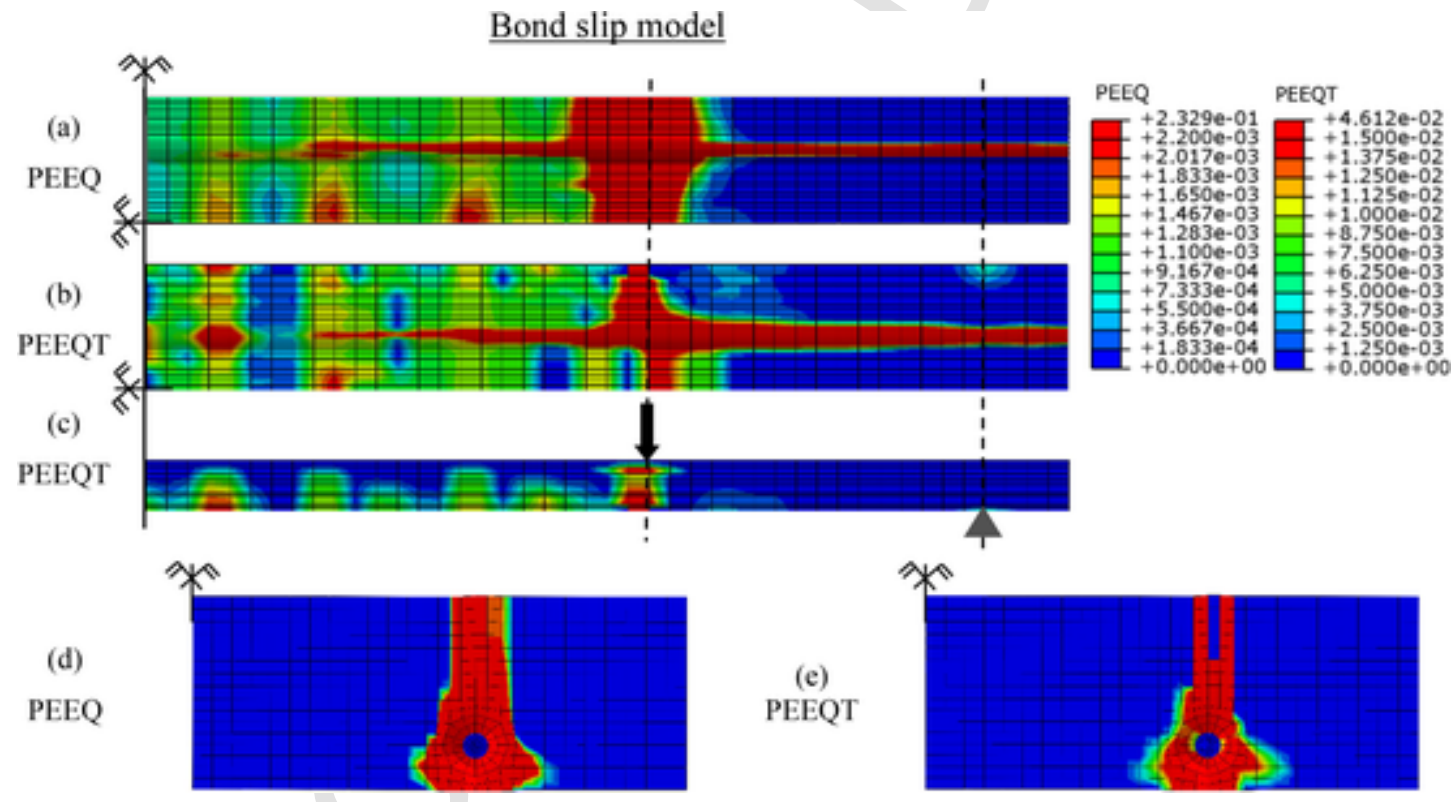

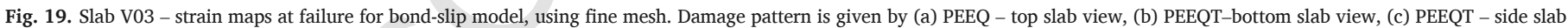
view, (d) PEEQ - cross section at the slab end, and (e) PEEQT-cross section at the slab end. Cross sections are given in deformed shape.

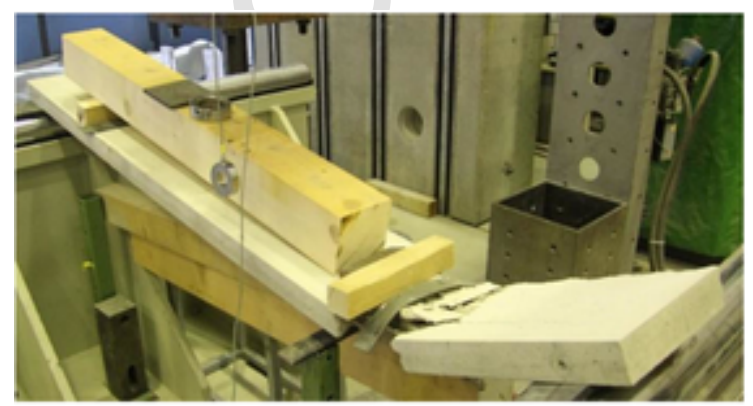

(a)

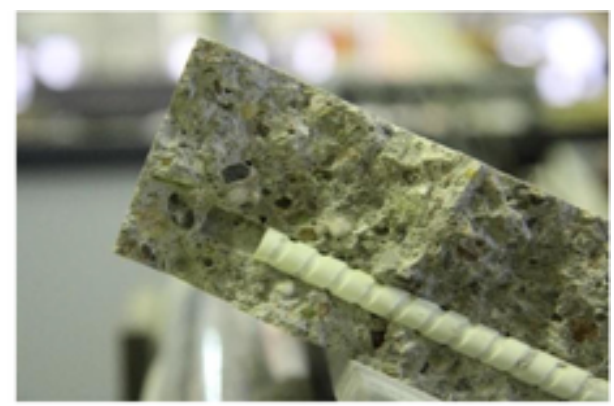

(b)

Fig. 20. Slab V03-damage at failure: (a) slab at testing setup, (b) detail of reinforcing bar debonding (photo courtesy of authors [43]). 
length, having in mind specimen geometry and test setup. The consequence of this choice is reflected on FE model damage concentrations representing experimental observed cracks, whereas the global response of thin GFRP RC member was matched in the case of the slabs V02 and V10.

Finally, in the case of V02, slab of standard thickness $(100 \mathrm{~mm})$ that failed due to concrete crushing, both bond modelling approaches, in combination with corresponding concrete laws, resulted in good match with the experimental result. Because of the above-mentioned reasons, the preference is however given to sufficiently fine mesh models. When it comes to very thin slabs, as V10 of $40 \mathrm{~mm}$ thickness that failed for the combination of concrete compressive failure and damage of concrete along the bars, both bond models matched sufficiently well the failure mode, while the preference is given to the bond-slip one, matching the failure load and corresponding deflection better. Here, the high capacity assigned to concrete in tension, in the case of perfect bond model, resulted in extended load and deflection capacity of the slab V10. Finally, in the case of the slab V03 of $60 \mathrm{~mm}$ thickness that failed for concrete splitting along the bar, only the bond-slip model reproduced the experimental result. Increased tensile capacity of tension stiffening concrete model, in perfect bond simulation, prevents the concrete splitting along the bar on the bottom slab side, thus yielding dangerous overestimation of member's capacity. Opposite to this, the use of plain concrete model in bond slip simulation resulted in correct failure mode. Thus, in the case of debonding failure, the main influence on the accuracy of numerical model is attributed to the concrete tensile law.

\section{Conclusions}

This work studied the effect of selected strategy for considering the concrete/bar interaction in the numerical modelling of thin GFRP RC slabs. Two strategies were adopted: perfect bond (indirect) and bond-slip behavior modelling (direct). Each strategy was associated with corresponding concrete tension model, that is, tension stiffening and plain concrete law, respectively. The numerical simulations were compared to experimental bending tests of thin GFRP RC slabs [43]. The bond modelling strategy, previously adopted for simulation of pull-out tests [41], was adopted herein to simulate the bond influence on structural components. Local bond-slip model obtained from the eccentric pull-out experimental tests [42] having the same GFRP bar, same concrete cover and similar concrete mechanical properties was employed in this study. Instead, in the case of perfect bond simulation, it was used the concrete tension stiffening law proposed by Bischoff and Paixao [26], suitable for concrete members reinforced with FRP bars. All performed FE numerical analysis were compared with the experimental test outcomes, as well as with the design guidelines predictions [23].

As for the numerical modelling accuracy, for slab of $100 \mathrm{~mm}$ thickness and concrete crushing failure (V02), both bond modelling approaches matched the experimental results in terms of force-displacement curves and failure mechanisms. However, with decreasing the slab thickness and changing the failure mode from crushing to debonding, the best accuracy was achieved with bond-slip model. Perfect bond model led to significant overestimation (non-conservative prediction) of the thin member capacity that failed due to bar debonding. A considerable contribution was of the employed concrete tensile laws. Considering relatively small number of simulations, the given hypothesis must be additionally confirmed. However, it underlines the need of additional studies for assessing the tension stiffening laws for such GFRP reinforced thin members in flexure, with specific attention to splitting of concrete cover along the reinforcing bars.

\section{Declaration of Competing Interest}

The authors declare that they have no known competing financial interests or personal relationships that could have appeared to influence the work reported in this paper.

\section{Acknowledgements}

The research was developed in the framework of the Marie Curie Initial Training Networks - "endure" European Network for Durable Reinforcement and Rehabilitation Solutions, project no: 607851. Prof. Dr.-Ing. Matthias Pahn and Dr.-Ing. Andreas Schmitt are gratefully acknowledged for providing the detailed insight into the experimental test data. The third author also acknowledges the support provided by FEDER and FCT funds within the scope of the project StreColesf (POCI-01-0145-FEDER-029485).

\section{References}

[1] CEB CEB-FIP Model Code 1990: Design Code. London, England: Thomas Telford Publishing for CEB (Comite Euro-International Du Beton); 1993.

[2] CEN EN 1992-1-1: 2004, Eurocode 2: Design of Concrete Structures - Part 1-1: General Rules and Rules for Buildings. Brussels, Belgium: CEN (European Committee for Standardization); 2004.

[3] Fib Model Code for Concrete Structures 2010. Berlin, Germany: Wiley Ernst \& Sohn; 2013.

[4] Fib Task Group 9.3 FRP Reinforcement in RC Structures (Bulletin 40). Lausanne, Switzerland: International Federation for Structural Concrete (fib); 2007.

[5] H. Abrishami, D. Mitchell Influence of splitting cracks on tension stiffening. ACI Struct J 1996;93(6):703-710. doi:10.14359/517.

[6] P.H. Bischoff Effects of shrinkage on tension stiffening and cracking in reinforced concrete. Can J Civ Eng 2001;28(3):363-374. doi:10.1139/100-117.

[7] C. Lin, A. Scordelis Nonlinear analysis of RC shells of general form. J Struct Div 1975;101(3):523-538.

[8] R. Gilbert, R. Warner Tension stiffening in reinforced concrete slabs. J Struct Div 1978;104(12):1885-1900.

[9] D.J. Carreira, K.-H. Chu Stress-strain relationship for reinforced concrete in tension. ACI J 1986;21-28.

[10] G. Prakhya, C. Morley Tension-stiffening and moment-curvature relations of reinforced concrete elements. ACI Struct J 1990;87(5):597-605.

[11] G. Kaklauskas A new stress-strain relationship for cracked tensile concrete in flexure. Statyba 1999;5(6):349-356. doi:10.1080/13921525.1999.10531489.

[12] L. Torres, F. López-Almansa, L. Bozzo Tension-stiffening model for cracked flexural concrete members. J Struct Eng 2004;130(8):1242-1251. doi:10.1061/ (ASCE)0733-9445(2004) 130:8(1242).

[13] A. Fantilli, P. Vallini, D. Ferretti, I. Iori Behaviour of R/C elements in bending and tension: the problem of minimum reinforcement ratio. Minimum Reinforcement in Concrete Members. European Structural Integrity Society; 1999. p. 99-125. doi:10.1016/S1566-1369(99)80063-6.

[14] A. Hillerborg, M. Modéer, P. Petersson Analysis of crack formation and crack growth in concrete by means of fracture mechanics and finite elements. Cem Concr Res 1976;6(6):773-781. doi:10.1016/0008-8846(76)90007-7.

[15] Z. Bažant, B. Oh Crack band theory for fracture of concrete. Matér Constr 1983;16(3):155-177. doi:10.1007/BF02486267.

[16] E.T. Ooi, Z.J. Yang Modelling crack propagation in reinforced concrete using a hybrid finite element-scaled boundary finite element method. Eng Fract Mech 2011;78(2):252-273. doi:10.1016/j.engfracmech.2010.08.002.

[17] H.V.S. GangaRao, N. Taly, P.V. Vijay Reinforced Concrete Design with FRP Composites. Boca Raton, FL: CRC Press, Taylor \& Francis Group; 2007.

[18] G. Fava, V. Carvelli, M. Pisani Remarks on bond of GFRP rebars and concrete. Compos B Eng 2016;93:210-220. doi:10.1016/j.compositesb.2016.03.012.

[19] S. Sólyom, M. Di Benedetti, A. Szijártó, G.L. Balázs Non-metallic reinforcements with different moduli of elasticity and surfaces for concrete structures. ACEE J Architect Civil Eng Environ 2018;11:279-288. doi:10.21307/ACEE-2018-025.

[20] A. Veljkovic, V. Carvelli, M. Haffke, M. Pahn Effect of small concrete cover on the fatigue behavior of GFRP bar and concrete bond. J Compos Constr 2019;23(2):1-13. doi:10.1061/(ASCE)CC.1943-5614.0000919. 04018082.

[21] L.C. Bank Composites for Construction. John Wiley \& Sons; 2006.

[22] Zhang Y, Lin X. Advances of finite element analysis for FRP concrete beams. In: The 5th International Conference on FRP Composites in Civil Engineering, Beijing, China, 2010.

[23] ACI Committee 440 Guide for the Design and Construction of Structural Concrete Reinforced with FRP Bars (ACI 440.1R-15). Farmington Hills, MI: ACI (American Concrete Institute); 2015.

[24] X. Lin, Y. Zhang Bond-slip behaviour of FRP-reinforced concrete beams. Constr Build Mater 2013;44:110-117. doi:10.1016/j.conbuildmat.2013.03.023.

[25] H. Salem, B. Hauke, K. Maekawa Fracture of concrete cover - its effect on tension stiffening and modeling. J Mater Conc Struct Pavements (JSCE) 1999;42(613):295-307. doi:10.2208/jscej.1999.613_295. 
[26] P. Bischoff, R. Paixao Tension stiffening and cracking of concrete reinforced with glass fiber reinforced polymer (GFRP) bars. Can J Civ Eng 2004;31(4):579-588. doi:10.1139/104-025.

[27] B. Massicotte, A. Nour, M. BenFtima, E. Yildiz EPM3D - A User-Supplied Constitutive Model for the Nonlinear Finite Element Analysis of Reinforced Concrete Structures (Report SR07-10). Montréal, Quebec: École Polytechnique de Montréal; 2007.

[28] A. Nour, B. Massicotte, E. Yildiz, V. Koval Finite element modeling of concrete structures reinforced with internal and external fibre-reinforced polymers. Can J Civ Eng 2007;34(3):340-354. doi:10.1139/106-140.

[29] Y. Zhang, X. Lin Nonlinear finite element analyses of steel/FRP-reinforced concrete beams by using a novel composite beam element. Adv Struct Eng 2013;16(2):339-352. doi:10.1260/1369-4332.16.2.339.

[30] V. Gribniak, G. Kaklauskas, L. Torres, A. Daniunas, E. Timinskas, E. Gudonis Comparative analysis of deformations and tension-stiffening in concrete beams reinforced with GFRP or steel bars and fibers. Compos B Eng 2013;50:158-170. doi:10.1016/j.compositesb.2013.02.003.

[31] I. Vilanova, L. Torres, M. Baena, M. Llorens Numerical simulation of bond-slip interface and tension stiffening in GFRP RC tensile elements. Compos Struct 2016;153:504-513. doi:10.1016/j.compstruct.2016.06.048.

[32] X. Lin, Y.X. Zhang Novel composite beam element with bond-slip for nonlinear finite-element analyses of steel/FRP-reinforced concrete beams. J Struct Eng 2013;139(12):1-6. doi:10.1061/(ASCE)ST.1943-541X.0000829. 06013003.

[33] E. Cosenza, G. Manfredi, R. Realfonzo Behavior and modeling of bond of FRP rebars to concrete. J Compos Constr 1997;1(2):40-51. doi:10.1061/ (ASCE)1090-0268(1997) 1:2(40).

[34] R. Jakubovskis, G. Kaklauskas, V. Gribniak, A. Weber, M. Juknys Serviceability analysis of concrete beams with different arrangements of GFRP bars in the tensile zone. J Compos Constr 2014;18(5):1-10. doi:10.1061/ (ASCE)CC.1943-5614.0000465. 04014005.

[35] H. Shima, L.-L. Chou, H. Okamura Micro and macro models for bond in reinforced concrete. J Facul Eng, Univ Tokyo 1987;39(2):133-194.

[36] O. Gooranorimi, G. Claure, W. Suaris, A. Nanni Bond-slip effect in flexural behavior of GFRP RC slabs. Compos Struct 2018;193:80-86. doi:10.1016/ j.compstruct.2018.03.027.

[37] L.C. Bank Progressive failure and ductility of FRP composites for construction: review. J Compos Constr 2013;17(3):406-419. doi:10.1061/ (ASCE)CC.1943-5614.0000355.

[38] E. Nigro, G. Cefarelli, A. Bilotta, G. Manfredi, E. Cosenza Fire resistance of concrete slabs reinforced with FRP bars. Part I: experimental investigations on the mechanical behavior. Compos B Eng 2011;42(6):1739-1750. doi:10.1016/ j.compositesb.2011.02.025.

[39] H. Hajiloo, M.F. Green, M. Noel, N. Benichou, M. Sultan Fire tests on full-scale FRP reinforced concrete slabs. Compos Struct 2017;179:705-719. doi:10.1016/ j.compstruct.2017.07.060.

[40] Dassault Systèmes Abaqus Software 6.14. Providence, RI, USA: Dassault Systèmes Simulia Corp; 2014

[41] M. Rezazadeh, V. Carvelli, A. Veljkovic Modelling bond of GFRP rebar and concrete. Constr Build Mater 2017;153:102-116. doi:10.1016/ j.conbuildmat.2017.07.092.

[42] A. Veljkovic, V. Carvelli, M. Haffke, M. Pahn Concrete cover effect on the bond of GFRP bar and concrete under static loading. Compos B Eng 2017;124:40-53. doi:10.1016/j.compositesb.2017.05.054.

[43] Schmitt A, Pahn M. Examination of the structural behavior of filigree GFRP-reinforced concrete slabs under bending. In: The Fourth International fib Congress, Improving Performance of Concrete Structures, Mumbai, India, 2014.

[44] F. Yan, Z. Lin Bond behavior of GFRP bar-concrete interface: damage evolution assessment and FE simulation implementations. Compos Struct 2016;155:63-76. doi:10.1016/j.compstruct.2016.07.078.
[45] ComBAR® Schöck, Schöck ComBAR Glass Fibre Reinforcement - Technical Information. Available: http://www.schoeck-combar.com/, August 2013 [Online].

[46] CSA Design and Construction of Building Structures with Fibre-Reinforced Polymers (CSA-S806-12). Mississauga, Ontario, Canada: Canadian Standards Association; 2012.

[47] M. Guadagnini, K. Pilakoutas, P. Waldron Shear performance of FRP reinforced concrete beams. J Reinf Plast Compos 2003;22(15):1389-1407. doi:10.1177/ 073168403035579 .

[48] S. Cholostiakow, M. Di Benedetti, K. Pilakoutas, M. Guadagnini Effect of beam depth on shear behavior of FRP RC beams. J Compos Constr 2019;23(1):4018075. doi:10.1061/(ASCE)CC.1943-5614.0000914.

[49] P. Kmiecik, M. Kaminski Modelling of reinforced concrete structures and composite structures with concrete strength degradation taken into consideration. Archiv Civil Mechan Eng 2011;11(3):623-636. doi:10.1016/S1644-9665(12)60105-8.

[50] M. Rezazadeh, S. Cholostiakow, R. Kotynia, J. Barros Exploring new NSM reinforcements for the flexural strengthening of RC beams: experimental and numerical research. Compos Struct 2016;141:132-145. doi:10.1016/ j.compstruct.2016.01.033.

[51] H. Cornelissen, D. Hordijk, H. Reinhardt Experimental determination of crack softening characteristics of normalweight and lightweight concrete. Heron 1986;31(2):45-56. http://resolver.tudelft.nl/uuid\%3a08c29b39-5c60-4ab6-b9d5643d11007f7c.

[52] D. Hordijk Local Approach to Fatigue of Concrete, PhD Thesis. Delft, Netherlands: Delft University of Technology; 1991.

[53] R. Gilbert Creep and shrinkage models for high strength concrete - proposals for inclusion in AS3600. Aust J Struct Eng 2002;4(2):95-106. doi:10.1080/ 13287982.2002.11464911.

[54] R. Jakubovskis, R. Kupliauskas, A. Rimkus, V. Gribniak Application of FE approach to deformation analysis of RC elements under direct tension. Struct Eng Mechan 2018;68(3):345-358. doi:10.12989/sem.2018.68.3.345.

[55] A. Scanlon, P.H. Bischoff Shrinkage restraint and loading history effects on deflections of flexural members. ACI Struct J 2008;105(4):498-506. doi:10.14359/ 19864.

[56] R.I. Gilbert Deflection calculation for reinforced concrete structures - why we sometimes get it wrong. ACI Struct J 1999;96(6):1027-1032. doi:10.14359/779.

[57] W.B. Krätzig, R. Pölling An elasto-plastic damage model for reinforced concrete with minimum number of material parameters. Comput Struct 2004;82(15-16):1201-1215. doi:10.1016/j.compstruc.2004.03.002

[58] J. VanMier Strain-Softening of Concrete under Multiaxial Loading Conditions. Eindhoven, Netherlands: Technische Hogeschool Eindhoven; 1984. doi: 10.6100/ IR145193.

[59] R. Vonk A micromechanical investigation of softening of concrete loaded in compression. Heron 1993;38(3):1-94. ISSN 0046-7316.

[60] Birtel V, Mark P. Parameterised finite element modelling of RC beam shear failure. In: Conference Proceedings - 2006 ABAQUS Users' Conference, Boston, MA, 2006.

[61] C. Chamis Mechanics of composite materials: past, present, and future. J Compos Tech Res 1989;11(1):3-14. doi:10.1520/CTR10143J.

[62] Bäker M. How to get meaningful and correct results from your finite element model, arXiv.org (Cornell University), 2018, arXiv:1811.05753.

[63] Veljkovic A, Carvelli V. Numerical modelling of GFRP reinforced thin concrete slabs. In: Proceedings of the XXIV Conference of the Italian Association of Theoretical and Applied Mechanics (AIMETA 2019), Rome, Italy, 2019.

[64] P. Feenstra, R. de Borst Aspects of robust computational modeling for plain and reinforced concrete. Heron 1993;38(4):1-76. http://resolver.tudelft.nl/ uuid\%3a9800c8aa-15b1-4286-a326-7dc65efdd33e. 